\title{
Engineering properties of strain hardening geopolymer composites with hybrid polyvinyl alcohol and recycled steel fibres
}

\author{
Yi Wang, Choi Lin Chan, Si Hang Leong, Mingzhong Zhang* \\ Department of Civil, Environmental, and Geomatic Engineering, University College London, \\ London, WC1E 6BT, UK
}

\begin{abstract}
Strain hardening geopolymer composite (SHGC) is an alkali-activated material reinforced with randomly dispersed short fibres, which exhibits high ductility and strain hardening and multiple cracking behaviour. This paper presents an experimental study on the effect of hybrid polyvinyl alcohol (PVA) and recycled tyre steel (RTS) fibres on engineering properties of fly ash-slag based SHGC cured at ambient temperature, including flowability, setting time, drying shrinkage, compressive strength and flexural behaviour in terms of stress-deflection response, first-crack strength and flexural strength, flexural toughness and toughening mechanisms. Four mix proportions of specimens with various volume fractions of hybrid PVA and RTS fibres including $1.5 \%$ PVA, $2 \%$ PVA, $1.75 \%$ PVA $+0.25 \%$ RTS and $1.5 \%$ PVA $+0.5 \%$ RTS were considered. The results indicated that the hybridisation of PVA fibre with RTS fibre led to a significant reduction in flowability, setting time and flexural strength of SHGC. However, the resistance to drying shrinkage and compressive strength of SHGC were greatly improved. Moreover, all specimens exhibited the expected deflection hardening behaviour with multiple stable microcracks formed over the tensile face of specimens under four-point bending. The addition of RTS fibre resulted in reduced crack widths in specimens where over $90 \%$ of cracks had a width of smaller than $60 \mu \mathrm{m}$. The mixture containing $2.0 \mathrm{vol} \%$ PVA fibre can be regarded as the optimal mixture for SHGC considering the strengths and deflection (or strain) hardening behaviour.
\end{abstract}

Keywords: Fibre reinforced concrete; Alkali-activated materials; Bendable concrete; Engineered geopolymer composites; Recycled fibre; Toughening mechanism

\section{Introduction}

Strain hardening cementitious composite (SHCC), a unique class of fibre reinforced cementitious composites, is featured by superior ductility and tensile strain capacity with a typical range of $2-5 \%$ against $0.01 \%$ of conventional concrete $[1,2]$. The extraordinary strain hardening behaviour and

\footnotetext{
Corresponding author. E-mail address: mingzhong.zhang@ucl.ac.uk (M. Zhang)
} 
steady-state micro-crack propagation (typically with a mean crack width of smaller than $100 \mu \mathrm{m}$ ) prevail SHCC in a wide range of engineering applications such as seismic resilient buildings, retrofitting project aiming at longer service life, and hydraulic structures requiring tight crack width [3-5]. However, the major drawback of SHCC is the low sustainability owing to the tremendous amount of carbon emission during fabrication of its binder, i.e. ordinary Portland cement (OPC), the production of which accounts for approximately 5-8\% of global carbon emission [6-9]. In recent years, geopolymers sourced from industrial or agricultural by-products such as fly ash (FA), ground granulated blast-furnace slag (GGBS), silica fume, and rice husk ash are increasingly considered as a promising alternative to OPC because of the low energy consumption, reduced greenhouse emissions, and superior mechanical properties, thermal performance and durability [10]. The substitution of OPC by geopolymers can lead to a substantial reduction of carbon emission by $55 \%$ $76 \%$ and energy consumption by around $36 \%[11,12]$.

Recently, strain hardening geopolymer composites (SHGC), also known as engineered geopolymer composites (EGC), have been developed by combining the advantages of SHCC and geopolymers. Many studies have been focused on either FA or GGBS based SHGC. For instance, Shaikh [13] studied the FA-based SHGC reinforced with PVA and steel fibres using steam curing and found that the specimens exhibited deflection hardening with multiple cracking behaviour. Ohno and Li [14] conducted a feasibility study on FA-based SHGC containing PVA fibre using different curing conditions and concluded that better performance of SHGC requires high temperature curing. The developed SHGC can achieve a very high ductility of $4 \%$ with the maximum and average crack widths of $117 \mu \mathrm{m}$ and $45 \mu \mathrm{m}$, respectively. Choi et al. [15] explored the GGBS-based SHGC reinforced with polyethylene (PE) fibre which attained a high tensile strength up to $13.06 \mathrm{MPa}$, strain capacity of up to $7.5 \%$ and an average crack width of $101 \mu \mathrm{m}$. Nevertheless, the low reactivity of low-calcium FA at ambient temperature resulted in long setting time and low early strength of SHGC which limits its use $[13,14,16]$. As such, heating curing is required, which makes it unsuitable for in-situ construction $[17,18]$. GGBS-based SHGC has quick setting, low workability and high shrinkage. To address these issues, a combination of FA and GGBS was favoured in the development of SHGC to achieve acceptable engineering properties at ambient curing condition. Nematollahi et al. [12] investigated the FA-GGBS based SHGC cured at ambient temperature, which had tensile strength and strain capacity of 4.6 MPa and 4.2\%, respectively. Shaikh et al. [19] compared the mechanical properties of 
FA-GGBS based SHGC reinforced with PE fibre and the counterpart OPC based composites and found that SHGC exhibited better performance than SHCC and the highest ultimate tensile strain along with maximum crack number was achieved when $0.75 \%-1.0 \%$ PE fibre was incorporated. Recently, Ling et al. [20] studied the effect of GGBS content on mechanical properties of FA-based SHGC and concluded that the increasing GGBS replacement ratio resulted in an increase in strengthrelated properties and reduction in ductility-related properties, which can be mainly ascribed to the enhanced density of SHGC matrix and fibre-matrix interface. The SHGC containing 20\% GGBS achieved the optimum mechanical properties with compressive strength and tensile strength of 102.3 $\mathrm{MPa}$ and $6.8 \mathrm{MPa}$, respectively.

Different fibres with various elastic modulus such as steel, polyvinyl alcohol (PVA), PE, polypropylene (PP) and polyethylene terephthalate (PET) fibres have been employed to produce SHGC, which have significant influences on mechanical properties of SHGC [21-23]. In general, SHGC reinforced with low modulus fibres, e.g. PP fibre with elastic modulus of 1.5-10 GPa, tends to exhibit low strength, high tensile strain capacity and large crack width. By contrast, SHGC containing high modulus fibres, e.g. steel fibre with elastic modulus of 200-210 GPa, tends to has high strength, low tensile strain capacity and fine crack width [24-26]. According to Farooq et al. [27], the incorporation of steel fibre or chopped steel wool fibre resulted in higher compressive strength (38.956.2 $\mathrm{MPa})$ and tensile strength $(2.1-5.35 \mathrm{MPa})$ but lower tensile strain capacity $(0.12 \%-0.42 \%)$. In addition, SHGC containing PVA fibre or PP fibre presented lower compressive strength (19.2-41 MPa) and tensile strength $(0.85-3.35 \mathrm{MPa})$ but higher tensile strain capacity $(0.52 \%-4 \%)$. Therefore, in order to achieve high strength and tensile strain capacity, SHCC and SHGC reinforced with hybrid fibres including both high and low modulus fibres have been developed to form synergistic effects. Previous studies have explored the effect of hybrid steel-PVA fibres on properties of SHCC. The results showed that strengths and energy absorption of SHCC were enhanced, whilst workability was reduced by the incorporation of steel fibre [28-31]. Wang et al. [29] found that the replacement of $0.5 \%$ PVA fibre with steel fibre in SHCC slightly improved the flexural strength and peak energy absorption by around $2 \mathrm{MPa}$ and $5 \mathrm{~kJ} / \mathrm{m}^{3}$, whereas the addition of $0.5 \%$ steel fibre enhanced the ultimate tensile strength from 2.84 $\mathrm{MPa}$ to $3.51 \mathrm{MPa}$. However, the fibre-balling effect was found with above $0.5 \%$ tyre steel fibre in SHCC, as reported by Mohammed et al. [28]. It was also proven that the inclusion of steel fibre in PVA-SHCC can improve the crack width control ability of the 
SHCC $[30,31]$. By introducing steel fibre in PP-SHGC, the toughness and equivalent flexural strength were enhanced with the increase of steel fibre content, whilst the improvement reduced when the total fibre content exceeded 1\%. The experiments conducted by Shaikh [13] on FA-based SHGC reinforced with hybrid PVA and steel fibres demonstrated superior deflection hardening behaviour for SHGC with 1\% PVA and 1\% steel fibres. Thus, the inclusion of hybrid metallic and polymeric fibres in SHGC is a possible way to increase the cost-effectiveness and engineering performance of the resultant composites.

About 5.2 billion tyres are estimated to be at the verge of disposal worldwide, which could result in adverse environmental impact and health hazards [32]. In recent decades, waste tyres have been increasingly utilised by energy recovery, recycling, and other approaches instead of ending up in landfills. The recycling of rubber particles, steel, and polymer fibres provides a promising way to mitigate the environmental and health problems, and produces economic benefits [33]. For example, recycling of waste tyres can help reduce carbon emissions by 1.52 tonnes annually [34]. Steel wire abstracted from waste tyres, known as recycled tyre steel (RTS) fibre, was reported as a potential substitute of manufactured steel fibre due to its better ductility and higher tensile strength, as the raw steel used in tyre production can have better quality than commercially available manufactured steel fibres [35]. Recently, an increasing number of studies have been focused on the effect of RTS fibre on engineering properties of fibre reinforced concrete (FRC). It was reported that the addition of RTS fibre within the critical fibre content (approximately $0.5 \mathrm{vol} \%$ ) can result in the slight enhancement of compressive strength of FRC, whereas excessive fibre content can lead to a reduction in compressive strength [28, 36-38]. Under flexural loading, RTS fibre reinforced composite can provide comparable performance with manufactured steel fibres and has sufficient crack restrain capability, which improves the post-crack resistance and energy absorption ability [32, 39]. Zhong and Zhang [40] presented an experimental study on engineering properties of hybrid RTS-PP fibre reinforced mortar and found that the inclusion of RTS fibre was effective in restraining the drying shrinkage and improving the flexural strength. The optimal mixture was found to be that with hybrid $0.5 \%$ RTS and $0.5 \%$ PP fibres, which resulted in the significantly enhanced post-cracking behaviour in terms of toughness indices and residual strength factors. Mohammed et al. [28] studied the engineering properties of concrete reinforced with hybrid RTS and PVA fibres and concluded that the combination of $0.5 \%$ PVA and $1.5 \%$ RTS fibres can lead to the optimum strengths (e.g. flexural strength and direct 
tensile strength). Moreover, an optimal ratio of $0.5 \%$ tyre wire and $1.5 \%$ PVA fibre was reported in SHCC considering the flexural strength, tensile strength, elastic modulus and shrinkage [28]. To date, the feasibility of hybridising RTS and PVA fibre to enhance the engineering properties of FA-GGBS based SHGC has not been studied.

The main purpose of this study is to experimentally investigate the synergetic effects of PVA and RTS fibres on engineering properties of FA-GGBS based SHGC cured at ambient temperature. The influences of PVA and RTS fibres were evaluated by increasing the PVA fibre volume fraction from $1.5 \%$ to $2.0 \%$ and the partial replacement of PVA fibre with $0 \%, 0.25 \%$ and $0.5 \%$ RTS fibre, respectively. A series of tests were conducted to measure the flowability, setting time, drying shrinkage, compressive strength and flexural performance of SHGC specimens with focus placed on deflection hardening behaviour in terms of stress-deflection response, first-crack strength and flexural strength, toughness (flexural toughness, toughness indices and ductility index), and toughening mechanisms. In addition, the cracking behaviour and failure mechanisms of SHGC under four-point bending were captured using a digital microscope. Based on the obtained experimental results, the optimal mix proportion for SHGC was proposed.

\section{Experimental Program}

\subsection{Raw materials}

The precursors used for synthesising geopolymer in this study were low-calcium FA (equivalent to ASTM Class F [41]) and GGBS. The chemical compositions and particle size distribution of FA and GGBS are demonstrated in Table 1 and Fig. 1, respectively. FA and GGBS have the specific gravity of 2.65 and 2.9 , and the average particle size of $53.60 \mu \mathrm{m}$ and $14.77 \mu \mathrm{m}$, respectively. A mixture of sodium hydroxide ( $\mathrm{SH}$ ) solution with a molarity of 10 and sodium silicate (SS) solution with a modulus ( $\mathrm{SiO}_{2}: \mathrm{Na}_{2} \mathrm{O}$ ratio) of $2.0\left(\mathrm{Na}_{2} \mathrm{O}: 15.35 \mathrm{wt} \%, \mathrm{SiO}_{2}: 29.79 \mathrm{wt} \%\right.$, water: $\left.54.86 \mathrm{wt} \%\right)$ was used as the alkaline activator in this study. The alkaline activator was mixed with a SS/SH ratio of 2.0. It was prepared by dissolving the SH powder in the tap water, followed by the addition of SS solution, which was then stored in the cupboard until its temperature became ambient to allow the heat dissipation caused by the exothermic chemical reaction in the mixed solution [20]. The modified polycarboxylate-based superplasticiser (SP) was added to improve the workability of the geopolymer composites and ensure a uniform fibre dispersion. Table 2 presents the properties of the SP (Sika ViscoFlow 2000), which was found to be effective in geopolymer binder activated by a mixture of 
$\mathrm{SH}$ and SS solution. It was reported that the addition of SP by $1 \mathrm{wt} \%$ of the geopolymer binder resulted in an increase in workability of the composite by $41 \%$ though a sacrifice of compressive strength by up to $15 \%$ [42]. Fine silica sand with a specific gravity of 2.65 and a maximum and mean particle size of $250 \mu \mathrm{m}$ and $148 \mu \mathrm{m}$ respectively was used as the aggregate. A preliminary absorption test indicated that the sand was in surface saturated dry (SSD) condition with an absorption rate of zero. In this study, PVA fibre supplied by Kuraray with a $1.2 \mathrm{wt} \%$ oil coating to control fibre-matrix interface properties [43] and RTS fibre supplied by Twincon Ltd were used as reinforcement for SHGC (see Fig. 2). The physical and mechanical properties of PVA and RTS fibres are given in Table 3.

\subsection{Mix proportions}

Table 4 lists the mix proportions used in this study. Based on previous studies [18, 44], the geopolymer binder was prepared with the FA-to-GGBS ratio of 0.8:0.2, alkaline activator-to-binder ratio of 0.4 , fine silica sand-to-binder ratio of 0.2 , and SPs-to-binder ratio of 0.01 , which were kept constant for all mixtures. The activator-to-binder ratio was calculated by the weight ratio of alkaline activator composed of SS and SH solution to geopolymer binder consisting of FA and GGBS. The studied parameters were the content of PVA and RTS fibres. In Table 4, 'P' and 'S' represent PVA and RTS fibres, respectively, while the denoted number stands for the corresponding fibre content in volume percentage. For instance, M2 (P1.5S0.5) represents the mixture containing 1.5 vol\% PVA and 0.5 vol\% RTS fibres. Four SHGC mixtures were studied and grouped into three series for the ease of comparison (i.e. mono, hybrid addition and hybrid replacement): (1) increasing PVA fibre content from 1.5 vol\% to 2.0 vol\% (M1 and M2); (2) addition of 0.5 vol\% RTS fibre in SHGC with 1.5 vol\% PVA fibre (M1 and M4); (3) RTS fibre partial replacement for PVA fibre in SHGC containing 2.0 vol\% PVA fibre at replacement levels of 0 vol\%, 0.25 vol\%, 0.5 vol\% (M2, M3, M4). In addition, the maximum RTS fibre dosage was set as 0.5 vol\% to avoid fibre-balling effect [28].

\subsection{Specimen preparation}

All SHGC mixtures were prepared using a 10 L Hobart mixer, and the entire mixing process typically lasted $7 \mathrm{~min}$ and $30 \mathrm{~s}$. Firstly, all solid ingredients were added in the mixer and dry mixed for $1 \mathrm{~min}$ until a homogeneous mix was obtained. Then, the alkaline activator was added gradually into the dry mixture and mixed for $1 \mathrm{~min}$. Afterwards, the addition of the SP was required to achieve an appropriate flowability and mixed for another $1 \mathrm{~min}$. The PVA fibre was then evenly applied to the 
mix to avoid the multifilament forms, followed by the RTS fibre. The fresh SHGC was poured into the moulds immediately after the mixing and then vibrated to allow the air bubble to escape and compact the SHGC. All specimens were covered with cling films to prevent moisture loss after casting and stored in the ambient environment for $24 \mathrm{~h}$. Subsequently, specimens were demoulded and covered with cling films and then stored in the curing room at an average temperature of $20 \pm$ $2{ }^{\circ} \mathrm{C}$ and relative humidity of $60 \pm 5 \%$ until testing ages.

\subsection{Testing methods}

\subsubsection{Flow table test}

Flow table test was conducted in accordance with ASTM C1437-15 [45] to determine the flowability of SHGC by measuring the spread diameter of fresh mortar immediately after mixing. The truncated mould with an upper diameter of $70 \mathrm{~mm}$, a lower diameter of $100 \mathrm{~mm}\left(D_{0}=100 \mathrm{~mm}\right)$ and a depth of $50 \mathrm{~mm}$ was filled with fresh SHGC on the wet flow table. The mould was lifted upwards, and the table was dropped 25 times in $15 \mathrm{~s}$. Four measurements of the diameter of each mixture were taken to obtain the average flow value, $D(\mathrm{~mm})$. The flow of the fresh SHGC specimen can be calculated as $\left(D-D_{0}\right) / D_{0} \times 100 \%$.

\subsubsection{Setting time test}

Setting time test was performed immediately after mixing according to ASTM C191 - 08 [46]. This was achieved by measuring the penetration depth of the fresh specimens using CONTROLS Vicamatic 4417 with a needle diameter of $1.13 \mathrm{~mm}$. The Vicat needle dropped into the specimen every $5 \mathrm{~min}$, and the penetrations were recorded. Setting time is the elapsed time between the addition of alkaline activator during initial mixing and the end point of determination recorded by Vicat needle. The initial setting time was the time when the penetration of the needle reached $25 \mathrm{~mm}$. The final setting time was recorded when the penetration measurement does not mark the specimen surface with a complete circular impression.

\subsubsection{Drying shrinkage test}

Drying shrinkage test was conducted in accordance with ASTM C490 [47] with $50 \times 50 \times 280 \mathrm{~mm}$ SHGC prisms on a daily basis. The prisms were exposed to the environment with a temperature of 20 $\pm 2{ }^{\circ} \mathrm{C}$ and relative humidity of $60 \pm 5 \%$. The change of length of the specimens was obtained using a digital gauge with an accuracy of $\pm 0.01 \mathrm{~mm}$. 


\subsubsection{Uniaxial compression test}

Uniaxial compression test was carried out on the $50 \times 50 \times 50 \mathrm{~mm}$ SHGC cubes according to ASTM C109-16 [48] to obtain the compressive strength of specimens at the ages of 1, 7 and $28 \mathrm{~d}$. The maximum load capacity of the machine CONTROLS C4600/FR was $2000 \mathrm{kN}$, and the loading rate of $1200 \mathrm{~N} / \mathrm{s}$ along with the peak sensitivity of $3 \mathrm{kN}$ was set for all specimens. For each curing age of the mixtures, the mean value of the compressive strength of three specimens was used to determine the compressive strength.

\subsubsection{Four-point bending test}

Four-point bending test was conducted according to ASTM C1609-05 [49] on an Instron 3345 with a maximum loading capacity of $5 \mathrm{kN}$ to determine the flexural strength and evaluate the deflection hardening behaviour of SHGC specimens. The mean values of flexural strength of three $400 \times 100 \times$ $20 \mathrm{~mm}$ prismatic specimens at 7 and $28 \mathrm{~d}$ of curing were obtained. The loading rate during the test was $1.6 \mathrm{~mm} / \mathrm{min}$, and the deflection was automatically recorded at an interval of $0.5 \mathrm{~s}$. The test terminated when one of the following failure criteria was met: 1) the load reached $4900 \mathrm{~N}, 2$ ) the deflection reached $105 \mathrm{~mm}, 3$ ) the load drop reached 150 N. Dino-Lite digital microscope was used to capture the image of cracks before unloading after the test terminated for determining the microcrack number and widths and capturing the status of fibres in the specimens.

Fig. 3 shows a typical load-deflection curve of SHGC, where point A denotes the first-crack load where the slope of the curve is zero and the deflection value at point $\mathrm{A}$ is $\delta$. The curve of SHGC specimens may display stable deflection hardening behaviour due to the formation of multiple microcracks, and therefore the turning point would be difficult to be identified. In this case, the limit of proportionality $\left(\mathrm{F}_{\mathrm{LOP}}\right.$ ) is used instead. According to ASTM C1609-05 [49], the first-crack strength (or limit of proportionality) and flexural strength of SHGC were calculated by

$\sigma_{f c}=\frac{P_{A} l}{b d^{2}}$

$\sigma_{f}=\frac{P l}{b d^{2}}$

where $\sigma_{f c}$ and $\sigma_{f}$ represent the first-crack strength (MPa) and ultimate flexural strength (MPa) of the specimen respectively, $P_{A}$ and $P$ stand for the first-crack load $(\mathrm{N})$ and ultimate load $(\mathrm{N})$ of the specimen respectively, $l$ is the load span of the specimen $(300 \mathrm{~mm}), b$ is the width of the specimen $(100 \mathrm{~mm})$, and $d$ is the depth of the specimen $(20 \mathrm{~mm})$. 
Toughness measures the energy absorbed by the material during plastic deformation. Low toughness materials tend to present brittle failure pattern, whereas high toughness materials are prone to exhibit prolonged plastic failure [50]. To reflect the data in the literature, this study analysed the toughness according to ASTM C1609 [49] and ASTM C1018 [51]. The ductility index (DI) was also used in comparison with the literature. The flexural toughness $\boldsymbol{T}_{\mathbf{1 5 0}}^{\boldsymbol{D}}$, defined in ASTM C1609 [49], was calculated as the area enclosed beneath the load-deflection curve up to the point of net deflection of L/150 (i.e. $2 \mathrm{~mm}$ ). The toughness indices $\left(\boldsymbol{I}_{\mathbf{5}}, \boldsymbol{I}_{\mathbf{1 0}}, \boldsymbol{I}_{\mathbf{2 0}}, \boldsymbol{I}_{\mathbf{3 0}}\right)$, as defined in ASTM C1018 [51], measures the energy absorption after the first crack. As shown in Fig. 3, points B, C, D, and E represent the deflection corresponding to $3 \delta, 5.5 \delta, 10.5 \delta$, and $15.5 \delta$, respectively. The toughness indices were calculated from the area under this curve by

$I_{5}=\frac{A_{O B}}{A_{O A}}$

$I_{10}=\frac{A_{O C}}{A_{O A}}$

$I_{20}=\frac{A_{O D}}{A_{O A}}$

$I_{30}=\frac{A_{O E}}{A_{O A}}$

where $\boldsymbol{A}_{\boldsymbol{O}}, \boldsymbol{A}_{\boldsymbol{O B}}, \boldsymbol{A}_{\boldsymbol{O}}, \boldsymbol{A}_{\boldsymbol{O}}, \boldsymbol{A}_{\boldsymbol{O}}$ denote the area beneath the load-deflection curve up to 1, 3, 5.5, 10.5, and 15.5 times the first-crack deflection, respectively, as shown in Fig. 3.

According to Shaikh [13], the ductility index $(D I)$ reflected the ductility of the material, which can be calculated using the following equation. If the peak load is not lower than the first-crack load, the material with higher $D I$ value tends to be more ductile.

$D I=\frac{\delta_{F}}{\delta_{A}}$

where $\delta_{F}$ is the deflection at peak load (mm), and $\delta_{A}$ is the deflection at first-crack load (mm).

\section{Results and discussion}

\subsection{Flowability}

The flowability is a parameter that can represent the workability of fresh SHGC mixtures. Fig. 4 shows the flow values of fresh SHGC mixtures with different fibre types and content. Higher flow value reflects better fluidity and workability, and thus the mix is easier for casting and compacting. As seen in Fig. 4, the flow values of fresh SHGC mixtures reduced with the increase of PVA fibre content and the addition of RTS fibre. SHGC mixture containing 1.5 vol\% PVA fibre (M1) had a flow 
value of $88.75 \%$. Compared to M1, when the PVA fibre content was increased to $2.0 \mathrm{vol} \%$, the flow value of the fresh mixture was reduced by $19.7 \%$, while the addition of 0.5 vol\% RTS fibre resulted in a significant reduction of flow value by $51.6 \%$. This reduction of flowability due to the increase of fibre content and the addition of RTS fibre shows a good agreement with the previous studies that adding 1.0 vol\% PVA fibre into geopolymer paste resulted in a flowability loss of over 40\% [52], while the addition of 1.0 vol\% RTS fibre led to a $59.1 \%$ reduction of flowability than that of the composite without RTS fibre [40], which can be ascribed to the rise of shear resistance in the fresh composites [53]. Besides, the workability of SHGC mixtures can also be influenced by various factors such as the shape, surface area, and aspect ratio of the fibre [24, 54].

The increase of RTS fibre partial replacement level of PVA fibre led to a reduction of flowability of fresh mixtures. In comparison with M2 (P2.0), when the PVA fibre was partially replaced by RTS fibre with the content of $0.25 \mathrm{vol} \%$ and $0.5 \mathrm{vol} \%$, the flow value of SHGC was decreased by $21.9 \%$ and 39.8\%, respectively. As shown in Fig. 2, RTS fibre had a non-uniform shape and geometry, which could increase the possibility of random fibre balling and agglomeration during the mixing process [55], which would lead to more contact networks between the fibre and matrix [56]. This contact mechanism allowed the fresh matrix to take extra loads and hence reduced the flowability of SHGC [57]. Also, the bundling effect of RTS fibre was more severe when a higher dosage of RTS fibre was applied in the matrix, which introduced more uncertainties to the results [28, 58]. It should be noted that the reduction of flowability would result in casting difficulties and increased volume of entrapped air, followed by the impairment of mechanical properties of SHGC.

\subsection{Setting time}

Fig. 5 shows the initial and final setting time of all mixtures. For the mono-PVA fibre reinforced SHGC mixtures, the setting time was slightly increased with the PVA fibre content. M1 had the initial and final setting time of $94 \mathrm{~min}$ and $130 \mathrm{~min}$, respectively. The increase of PVA fibre content from $1.5 \mathrm{vol} \%$ to $2.0 \mathrm{vol} \%$ resulted in a slight delay of initial and final setting time by $14.9 \%$ and $8.0 \%$, respectively. The longer setting time of SHGC mixtures was directly related to the slower geopolymerisation process. This can be explained by the fact that PVA fibre was covered with hydrophobic oil coatings, as a result of which its hydrophilicity was reduced. The increase of fibre content resulted in a higher amount of air voids induced in the mixture and the delayed geopolymerisation process, as air has a lower thermal conductivity compared to matrix [24]. However, 
the addition of RTS fibre by 0.5 vol\% into SHGC mixture resulted in a decrease of setting time. Compared to M1, the incorporation of $0.5 \mathrm{vol} \%$ RTS fibre shortened the initial and final setting time by $14.2 \%$ and $25.9 \%$, respectively. This can be attributed to the hydrophilic surface of RTS fibre and its absorption of the water within the mixture, which led to an increase of effective concentration of alkaline activator and further decreased setting time $[59,60]$. The consumption of alkaline activator also resulted in the reduction of alkaline activator for dissolution of geopolymer binder, which in turn reduced the level of geopolymerisation [61-63].

For RTS fibre partial replacement of PVA fibre, the setting time was shortened by the RTS fibre replacement. The reference SHGC mixture (M2) had the initial and final setting time of 108 min and $140 \mathrm{~min}$, respectively. The replacement of $0.25 \mathrm{vol} \%$ PVA fibre with RTS fibre resulted in the reduction of initial and final setting time by $35.3 \%$ and $38.5 \%$, respectively. When the replacement level was increased to $0.5 \mathrm{vol} \%$, the initial and final setting time was reduced by $25.3 \%$ and $31.3 \%$, respectively. The reduction of setting time with the RTS fibre partial replacement of PVA fibre can be attributed to the higher hydrophilicity of RTS fibre than that of oil-coated PVA fibre. Water within specimens containing RTS fibre would be absorbed, leading to the acceleration of geopolymerisation process $[59,60]$. However, SHGC mixture with higher-level RTS fibre replacement $(0.5 \mathrm{vol} \%)$ had $15.4 \%$ and $11.6 \%$ longer initial and final setting time than that of SHGC mixture with lower-level RTS fibre replacement (0.25 vol\%). A similar explanation could be applied in this case: the higher dosage of RTS fibre could lead to more voids in the mixture and thereby delaying the geopolymerisation process [24]. It is worth mentioning that setting time is an essential property because short setting time can cause difficulties during mixing and casting procedure, and thereby affecting the feasibility and application of fresh mixes.

\subsection{Drying shrinkage}

Drying shrinkage is the consequence of the loss of capillary water in hardening composites, which can potentially result in deformation and cracks in structural elements [24]. The drying shrinkage of all mixtures with different hybrid fibre content is presented in Fig. 6. Overall, the shrinkage of all specimens exhibited sharp drops at early ages due to the rapid reduction of internal relative humidity with the loss of capillary water [64], followed by a decreasing rate of declines because of restrictions by the interfacial bonds of fibre and matrix within SHGC specimens [50]. The strength of the interfacial bonds developed progressively as a result of geopolymerisation, and thus this growth was 
more rapid at early ages [65].

As seen in Fig. 6, the drying shrinkage of mono-PVA fibre reinforced SHGC specimens at $28 \mathrm{~d}$ was increased by $52.7 \%$ with the increase of fibre content from $1.5 \mathrm{vol} \%$ to $2.0 \mathrm{vol} \%$. The increase of fibre content was anticipated to result in a reduction of drying shrinkage [24]. However, the contrary results observed here can be ascribed to the weakened fibre-matrix interface due to the oilcoated surface of PVA fibres. The weaker interaction could lead to debonding by expanding the gap between fibre and its surrounding matrix, which curtailed the stress transferring in SHGC specimens and reduced the resistance to shrinkage [66]. In addition, the increased fibre content could cause the poor compaction and higher porosity of the mixtures. The formed pore network allows the moisture to move towards the surface of specimens $[24,53,67]$. By contrast, with the addition of RTS fibre in SHGC containing 1.5 vol\% PVA fibre, a significant drop of drying shrinkage by $58.1 \%$ at $28 \mathrm{~d}$ can be observed, which can be attributed to the high elastic modulus of RTS fibre and the strong RTS fibre-matrix interaction induced by its hydrophilic nature and large surface area $[66,68]$.

In the hybrid replacement series of SHGC specimens, the reduction trend was even more evident with the increased replacement level. Compared to SHGC specimens with 2.0 vol\% mono-PVA fibre, the replacement of PVA fibre by $0.25 \mathrm{vol} \%$ and $0.5 \mathrm{vol} \%$ RTS fibre resulted in a significant reduction of 28 -d drying shrinkage by $62.0 \%$ and $72.5 \%$, respectively. This can be ascribed to the high elastic modulus of RTS fibre and the strong RTS fibre-matrix interaction. This finding is consistent with the previous study that the inclusion of $0.5 \mathrm{vol} \%$ micro steel fibre led to a reduction of drying shrinkage by $25 \%$, and the inclusion of $2.0 \mathrm{vol} \%$ and higher dosage of micro steel fibre can even result in an almost negligible value of drying shrinkage [68]. Thus, it can be concluded that applying RTS fibre is an effective approach to control the shrinkage of SHGC.

\subsection{Compressive strength}

Fig. 7 shows the failure mode of SHGC cubes under compression. Instead of a typical brittle failure of breaking into parts through visible major cracks, all SHGC specimens remained their original shapes with minimal debris as the compression-induced tensile crack propagation was arrested by the fibres that provided extra energy for resisting the tensile stress in the cube [69]. Fig. 8 displays the effect of hybrid fibre content on compressive strength of SHGC at 1, 7 and $28 \mathrm{~d}$. In general, the compressive strength of all mixtures increased gradually with increasing curing age due to the geopolymerisation process. SHGC containing 1.5 vol\% PVA fibre had a 1-d compressive strength of 
13.1 MPa, which was increased by $132.1 \%$ and $155.8 \%$ at 7 and $28 \mathrm{~d}$, respectively. With the increase of PVA fibre content from $1.5 \mathrm{vol} \%$ to $2 \mathrm{vol} \%$, the compressive strength of SHGC was improved by $34.7 \%$ at $1 \mathrm{~d}$ but slightly reduced by $9.7 \%$ and $7.3 \%$ at 7 and $28 \mathrm{~d}$. The increase of compressive strength with increasing fibre content at early age can be ascribed to the more energy of fracture required to pull fibres out [70]. However, this effect could be altered by the inadequate compaction of SHGC specimens, leading to an increase of porosity and decrease of strength. The addition of RTS fibre into the mono-PVA system of SHGC specimens resulted in an increase of compressive strength. By adding 0.5 vol\% RTS fibre in SHGC containing 1.5 vol\% PVA fibre, the compressive strength of SHGC specimens at $28 \mathrm{~d}$ was increased by $16.7 \%$, from $33.51 \mathrm{MPa}$ to $39.1 \mathrm{MPa}$. This can be attributed to the high stiffness and hydrophilicity nature of RTS fibre, which can absorb more energy and provide strong fibre-matrix interaction $[24,66,70]$.

Regarding the hybrid fibre system of SHGC specimens, the partial RTS fibre replacement of PVA fibre showed various effects on compressive strength at different ages. At the early ages ( 1 and $7 \mathrm{~d}$ ), the replacement level of RTS fibre had a marginal effect on compressive strength of SHGC specimens, whereas a clear trend at $28 \mathrm{~d}$ indicated that the compressive strength increased with the replacement of RTS fibre. For example, M2 (P2.0) had the highest compressive strength of $17.65 \mathrm{MPa}$ at $1 \mathrm{~d}$ and the lowest compressive strength of $27.46 \mathrm{MPa}$ at $7 \mathrm{~d}$. In comparison, M3 (P1.75S0.25) presented the lowest compressive strength at $1 \mathrm{~d}(14.1 \%$ lower than M2) and the highest compressive strength at 7 d (9.4\% higher than M2). At 28 d, when the PVA fibre was replaced by RTS fibre with content of $0.25 \mathrm{vol} \%$ and $0.5 \mathrm{vol} \%$, the compressive strength of SHGC specimens was gradually increased by $13.9 \%$ and $25.9 \%$, respectively. The variation of compressive strength can be attributed to the random orientation and distribution of incorporated fibres. Fig. 9a illustrates an example of the orientation of RTS and PVA fibres in the crack of the failed SHGC cube (M4), where RTS fibre was found to be in parallel to the crack propagation direction and hence was ineffective for resisting the crack. As shown in Fig. 9b, PVA fibres were unevenly distributed across the crack. Since the delay of crack initiation and propagation is highly dependent on the fibre orientation and dispersion, the randomly distributed fibre would adversely affect the stability of results. Moreover, more voids were generated in the hybrid PVA-RTS fibre reinforced SHGC due to the inclusion of RTS fibre that has relative irregular shapes and various lengths [57]. The inhomogeneous internal structure of composites would ultimately decrease the compressive strength and result in the inconsistent compressive performance 
of SHGC. This was manifested from the large standard deviations of the results of the hybrid replacement series with higher fibre content, as seen in Fig. 8.

\subsection{Deflection hardening behaviour}

This section discusses the deflection hardening behaviour of SHGC specimens under four-point bending in terms of stress-deflection response, first-crack strength and flexural strength, and toughness such as flexural toughness, toughness indices, and ductility index, as well as toughening mechanisms. Table 5 presents the flexural properties of SHGC specimens, including the first-crack deflection, ultimate flexural deflection, ductility index, flexural toughness, crack number and crack width.

\subsubsection{Stress-deflection response}

Fig. 10 shows the stress-deflection relationship of all SHGC specimens. Overall, all specimens exhibited similar response under four-point bending. For each specimen, the increment of stress was directly proportional to the vertical deflection until it reached the first-crack (or limit of proportionality, $\mathrm{F}_{\mathrm{LOP}}$ ) point, after which the curve became non-linear with significantly reduced slope, and the specimen entered the deflection hardening stage. Finally, the maximum stress of the specimen was reached, followed by the failure of the specimen. In the mono-PVA system (Fig. 10a-b), the stress-deflection curve of the specimen tended to show a stress drop immediately after the first-crack point, followed by the wavy curve in the deflection hardening stage due to the formation of microcracks. The stress drop manifested the different crack widths, and a higher drop on the stressdeflection curve indicated a larger crack opening. The crack opening resisted by fibres due to the bridging effect allowed the formation of multiple microcracks on the tensile face of the specimen. In the hybrid PVA-RTS systems (Fig. 10c-d), the stress-deflection curves of the specimens were smoother, and smaller stress drops can be observed. The differences between the curves of a monoPVA system and a hybrid PVA-RTS system can be attributed to the characteristics of fibres and the interaction between matrix and fibres. The deformation of PVA fibre in the cracking zone enlarged the crack widths. Then, the bridging effect of PVA fibre allowed the flexural stress to be well distributed across the specimen, resulting in the enhancement of deflection capacity of SHGC specimens. Compared to PVA fibre, RTS fibre has a higher stiffness, greater length and irregular shape, which might be damaged in the recycling process [32]. Therefore, the friction between RTS fibre and matrix was stronger, which would limit the stress drops in the stress-deflection curves. As a 
result, the crack width and deflection of SHGC specimens are limited.

Since the cracking behaviour is essential for structural design in terms of serviceability limit state and durability, the crack control ability is assessed with the cracking patterns and quantified by crack numbers along with crack widths [71]. Fig. 11 displays the crack patterns at the failure of each mixture under four-point bending. All cracks were captured right after the test terminated to avoid difficulties of tracing the cracks due to the closure of some microcracks when the load was removed [72]. As illustrated in Fig. 11, multiple microcracks can be observed for all mixtures, which conformed to their good deflection hardening behaviour. For the mono-PVA system of SHGC specimens (Fig. 11a-b), the microcracks were uniformly distributed along the test span, which indicated that the stress was evenly distributed and resulted in a higher ultimate deflection. However, in the hybrid PVA-RTS systems (Fig. 11c-d), the cracks were randomly dispersed with varying crack spacings on the specimen, suggesting that the stress was not well dispersed on the test span. In particular, the crack deflection and crack branching shown in Fig. 11d can be ascribed to the utilisation of high stiffness RTS fibre, which prevented the crack propagation along a certain path and increased the effective crack path to release stress [24]. Consequently, the hybrid PVA-RTS fibre reinforced SHGC showed smaller deflections (see Fig. 10). These findings agree well with a previous study that the saturation of micro-cracking behaviour was strongly related to the flexural deflection [68].

Fig. 12 shows the crack number and crack width distribution obtained from the images captured using the Dino-Lite digital microscope. The crack number and average crack width of SHGC specimens are presented in Table 5. M2 (P2.0) had the minimum average crack number of 99 among all mixtures along with the maximum average crack width of $80 \mu \mathrm{m}$. When the PVA fibre was partially replaced by RTS fibre with the content of 0.25 vol\% and 0.5 vol\%, the crack number of SHGC specimens was increased by $47.0 \%$ and $41.6 \%$, respectively, while the average crack width was significantly reduced by $62.7 \%$ and $73.0 \%$, respectively. As seen in Fig. 12, approximately $81.1 \%$, $40.6 \%, 92.2 \%$, and $96.0 \%$ cracks had a crack width of less than $60 \mu \mathrm{m}$ in M1 (P1.5), M2 (P2.0), M3 (P1.75S0.25), and M4 (P1.5S0.5). This is in good agreement with the previous discussion on stressdeflection curves and cracking patterns.

\subsubsection{First-crack strength and flexural strength}

Figs. 13 shows the first-crack strength and flexural strength of all specimens at $7 \mathrm{~d}$ and $28 \mathrm{~d}$. Overall, the first-crack strength and flexural strength of all mixtures were enhanced with curing age due to the 
geopolymerisation process. For example, M1 (P1.5) had 7-d first-crack strength and flexural strength of 2.96 MPa and 5.84 MPa, respectively, both of which experienced an increase of $2.5 \%$ at $28 \mathrm{~d}$. At $7 \mathrm{~d}$, compared to M1 (P1.5), the first-crack strength was reduced by $28.9 \%$ with the increase of PVA fibre content to $2.0 \mathrm{vol} \%$, but was increased by $10.9 \%$ with the addition of RTS fibre into M1 (P1.5). Similar experimental findings on the hybrid steel and PP fibre reinforced geopolymers were reported by Sukontasukkul [73] that increasing steel fibre from $0.2-2.0$ vol\% (PP content kept at 1 vol\%) increased the first peak load from $8.7 \mathrm{kN}$ to $11.5 \mathrm{kN}$. The improvement of first-crack strength was given by the increase of fibre volume fraction, regardless of the fibre type. For hybrid PVA-RTS system of mixtures, the RTS fibre replacement by $0.25 \mathrm{vol} \%$ and $0.5 \mathrm{vol} \%$ resulted in gradual enhancement of first-crack strength by $22.6 \%$ and $55.9 \%$, respectively. However, the effect of fibre was different at $28 \mathrm{~d}$. When increasing PVA fibre content from $1.5 \mathrm{vol} \%$ to $2.0 \mathrm{vol} \%$ or adding RTS fibre into M1 (P1.5), the first crack strengths of SHGC specimens were improved by $13.2 \%$ and 13.7\%, respectively. The RTS fibre partial replacement of PVA fibre had a marginal effect on firstcrack strength of SHGC mixtures. Only a reduction of $1.70 \%$ was observed when 0.25 vol\% PVA fibre was replaced, whereas $0.45 \%$ increase was observed when 0.5 vol\% PVA fibre was replaced.

As the PVA fibre content increased from 1.5 vol $\%$ to 2.0 vol $\%$, the flexural strength of SHGC at $7 \mathrm{~d}$ and $28 \mathrm{~d}$ was increased by $37.50 \%$ and $40.72 \%$, respectively. However, the addition of 0.5 vol $\%$ RTS fibre in M1 (P1.5) had a negligible effect on flexural strength of SHGC, which was reduced by $2.49 \%$ at $7 \mathrm{~d}$ and increased by $7.21 \%$ at $28 \mathrm{~d}$. For hybrid replacement series, the replacement of PVA fibre by RTS fibre led to a pronounced decrease of flexural strength. At $7 \mathrm{~d}$, by replacing 0.25 vol\% and 0.5 vol\% PVA fibre with RTS fibre, the flexural strength of the specimens was reduced by $29.65 \%$ and $29.08 \%$. At $28 \mathrm{~d}$, when 0.25 vol\% and 0.5 vol\% PVA fibre was replaced with RTS fibre, the flexural strength of specimens was reduced by $21.87 \%$ and $23.81 \%$, respectively. As discussed, the fibre bridging effect was mainly provided by the PVA fibre in the hybrid fibre reinforced SHGC. Thus, the increase of RTS fibre content (i.e. reduction of PVA fibre content) can negatively affect the strain hardening characteristics and in turn the flexural strength. Owing to the irregular geometry characteristics of RTS fibre caused by the recycling process [39], the post-crack performance of SHGC containing RTS fibre would be reduced and thus resulted in the large discrepancy between specimens. To minimise this variation, RTS fibre with poor quality can be filtered before applying them in the SHGC. Also, careful attention should be paid when adding the fibres to the matrix because 
well oriented and distributed fibres are beneficial to the toughening mechanisms, leading to better mechanical properties of SHGC.

\subsubsection{Toughness}

In this study, toughness was measured by flexural toughness, toughness indices, and ductility index. The flexural toughness, $T_{150}^{D}$, was used to quantify the toughening mechanisms and present the amount of energy that can be absorbed by SHGC. The results of the flexural toughness of each mixture are demonstrated in Fig. 14 and Table 5. In general, the flexural toughness of all mixtures was increased slightly with increasing curing age because of the increase of geopolymer matrix strength. The flexural toughness of mono-PVA system of SHGC at $7 \mathrm{~d}$ and $28 \mathrm{~d}$ was increased by $2.39 \%$ and $17.58 \%$ respectively with the increase of PVA fibre content from $1.5 \mathrm{vol} \%$ to $2.0 \mathrm{vol} \%$. When adding $0.5 \%$ RTS fibre into M1 (P1.5), the flexural toughness of SHGC was increased by 14.64\% and $14.93 \%$ at $7 \mathrm{~d}$ and $28 \mathrm{~d}$, respectively. Regarding the RTS fibre partial replacement series, the flexural toughness was enhanced gradually with the replacement level of RTS fibre at $7 \mathrm{~d}$ and slightly decreased at $28 \mathrm{~d}$. At $7 \mathrm{~d}$, the flexural toughness was increased by $4.41 \%$ and $11.97 \%$ when 0.25 vol\% and 0.5 vol\% PVA fibre was replaced by RTS fibre. At $28 \mathrm{~d}$, the RTS fibre replacement resulted in a reduction in flexural toughness by approximately $2.5 \%$, regardless of replacement level. This can be explained by the fact that the high RTS fibre content can cause difficulty in mixing and poor fibre dispersion, which adversely affect the flexural performance of SHGC. Additionally, independent of the hybrid type, the inclusion of RTS fibre was found to be effective for increasing the flexural toughness at early ages.

The toughness indices were obtained to estimate the energy absorption ability of SHGC after the first crack occurred. As reported by Shaikh [13], composites with toughness indices $I_{10}>10$ and $I_{20}>$ 20 can be considered as deflection hardening materials. Fig. 15 shows the toughness indices of each mixture, which indicated both mono-PVA fibre and hybrid PVA-RTS fibre reinforced SHGC in this study fulfilled this requirement. The difference between $I_{5}$ and $I_{10}$ among all mixtures can be negligible. At $7 \mathrm{~d}, \mathrm{M} 2$ (P2.0) demonstrated the best performance in terms of toughening characteristics with the highest $I_{30}$ of 62.98 . This higher post-cracking toughness was achieved owing to the fibre bridging mechanism provided by the low modulus PVA fibres [24]. However, the addition of $0.5 \%$ RTS fibre to the mono-PVA fibre reinforced SHGC was found less effective for improving the post-crack energy absorption. This further implies that the deflection hardening performance of 
hybrid PVA-RTS fibre reinforced SHGC was mainly dependent on the PVA fibre. Regarding the hybrid replacement series, the RTS fibre replacement resulted in a reduction of $I_{30}$ by $14.7 \%$ and $26.8 \%$ for M3 (P1.75S0.25) and M4 (P1.5S0.5), respectively, which can be ascribed to the lower dosage of PVA fibre (i.e. less PVA fibres bridging the cracks) in these mixtures. However, the effect of fibres was different at $28 \mathrm{~d}$. The increase of PVA fibre by $0.5 \mathrm{vol} \%$ had a negligible effect on $I_{30}$, whereas the addition of 0.5 vol\% RTS fibre resulted in an enhancement of $I_{30}$ by $19.6 \%$. For the hybrid PVARTS system, $I_{30}$ was increased by $11.0 \%$ and $19.7 \%$ when PVA fibre was replaced by RTS fibre with the level of $0.25 \mathrm{vol} \%$ and $0.5 \mathrm{vol} \%$, respectively. Compared to the mono-PVA system, the incorporation of RTS fibre resulted in the different trend due to the hydrophilic surface of RTS fibre [66]. The RTS fibre with a hydrophilic surface has a stronger bond with the geopolymer matrix than that of oil-coated PVA fibre and thus SHGC containing a higher content of RTS fibre could absorb more energy before the bond between fibre and matrix was broken.

The ductility index of SHGC specimens is illustrated in Fig. 16. In general, the ductility index of all mixtures was reduced slightly with increasing curing age along with the reduction of ultimate deflection due to the increase of geopolymer matrix strength. With the increase of PVA fibre content from $1.5 \mathrm{vol} \%$ to $2.0 \mathrm{vol} \%$, the ductility index of SHGC was increased by $59.8 \%$ and $26.4 \%$ at $7 \mathrm{~d}$ and $28 \mathrm{~d}$, respectively. The addition of RTS fibre by $0.5 \mathrm{vol} \%$ led to a reduction of ductility index by $38.3 \%$ and $33.8 \%$ at $7 \mathrm{~d}$ and $28 \mathrm{~d}$, respectively. For the RTS fibre partial replacement series, the replacement level of $0.25 \mathrm{vol} \%$ and $0.5 \mathrm{vol} \%$ resulted in a drop of ductility index by $47.4 \%$ and $61.4 \%$ at $7 \mathrm{~d}$, and $40.8 \%$ and $47.6 \%$ at $28 \mathrm{~d}$, respectively.

\subsubsection{Toughening mechanisms}

The deflection hardening behaviour and energy absorption ability of SHGC are directly related to different toughening mechanisms with various fibre types, including PVA fibre bridging, PVA fibre rupture, PVA fibre pull-out, RTS fibre bridging, RTS fibre debonding, and hybrid PVA-RTS system, as shown in Fig. 17. When the specimen was subjected to the bending load, it started to deform and crack between the two loading pins where the flexural stress was maximum. The first crack of composites was initiated once the bending capacity of the matrix was exceeded. Then, the crack kept propagating until it reached a PVA fibre with low stiffness. At this point, the fibre might be elongated, ruptured or pulled out since the crack tried to pass through it due to the applying flexural stress.

The PVA fibre bridging mechanism occurred when the fibre underwent the stress by deforming 
until it yielded and ruptured. This bridging effect arose when the friction between fibre and matrix was adequate to avoid fibre pull-out [66]. The geopolymisation product adsorbed on the PVA fibres surface indicated that the bond strength could be strong enough to trigger this mechanism. By contrast, the weaker interfacial bond strength compared to the applied stress resulted in the fibre pull-out. The localised stress was re-distributed by the fibre bridging, and multiple microcracks were formed on the specimens. The continuous process of the formation of microcracks led to an increase in the ductility and post-cracking toughness, as discussed in Section 3.5.3. This also agrees with the observed cracking patterns of M1 (P1.5) and M2 (P2.0) in Fig. 11a-b that illustrate the uniformly distributed microcracks along the test span.

The toughening mechanism was different for RTS fibre that has a higher stiffness and irregular geometry as opposed to PVA fibre. As shown in Fig. 17f, the PVA fibre was elongated and deformed while the RTS fibre remained its shape. When the crack reached the RTS fibre, the fibre-matrix debonding (see Fig. 17e) took place due to its high stiffness that prevented the RTS fibre from deforming. Typically, in SHGC with only high stiffness fibres, the fibres would debond, slide and be pulled out when the applied stress overcomes the bond strength, as a result of which a sudden release of localised stress and formations of macrocracks would occur [66]. Therefore, it can be deduced that the deflection hardening behaviour of hybrid PVA-RTS fibre reinforced SHGC was mainly functioned by the PVA fibre bridging effect. Regarding the inclusion of RTS fibre that has high friction with its surrounding geopolymer matrix compared to PVA fibre due to the large surface area, inherent hydrophobicity and irregular shape, the pre-crack toughness of SHGC (quantified as the flexural toughness $T_{150}^{D}$ in Section 3.5.3) was improved due to the additional energy absorption ability given by the strong RTS fibre-matrix interaction [66].

To sum up, the efficiency of fibre reinforcement in SHGC is dependent on the optimal mobilisation of all enhancement mechanisms mentioned above. As observed in the digital images, the three main factors governing the toughening mechanisms are fibre stiffness, fibre-matrix interaction and fibre dispersion. The low stiffness PVA fibre and moderated PVA fibre-matrix interaction contributed to the bridging mechanism and in turn, improved the deflection hardening behaviour of SHGC. In contrast, the high stiffness of RTS fibre prevented itself from deforming and rupturing in SHGC, which improved the pre-cracking energy absorption of SHGC. However, the varying geometry and surface characteristics of RTS fibre led to a high scatter of experimental results. 
Besides, the poor fibre dispersion causes the uneven stress distribution in SHGC, and the energy absorption would be reduced accordingly.

\section{Conclusions}

This paper investigated the engineering properties of fly ash-slag based strain hardening geopolymer composites (SHGC) reinforced with hybrid polyvinyl alcohol (PVA) and recycled tyre steel (RTS) fibres cured at ambient temperature. The effects of fibres on engineering properties of SHGC including flowability, setting time, drying shrinkage, compressive strength and deflection hardening behaviour were estimated by increasing the PVA fibre content from 1.5 vol\% to 2.0 vol\%, adding RTS fibre $(0.5$ vol\%), and changing the partial replacement of PVA fibre with RTS fibre (0.25 vol\% and $0.50 \mathrm{vol} \%$ ) in the mono-PVA fibre reinforced SHGC mixtures. Based on the experimental results, the main conclusions can be drawn as follows:

- The flowability was reduced by $19.7 \%$ and $51.6 \%$ respectively with the increase of PVA fibre content and the addition of RTS fibre into the mixture due to the rise of shear resistance in the fresh composites. The replacement of PVA fibre by RTS fibre with replacement level of 0.25 vol\% and 0.5 vol $\%$ also resulted in a reduction of flowability by $21.9 \%$ and $39.8 \%$ respectively, which can be ascribed to the increased fibre-matrix contact induced by the non-uniform shape and geometry of RTS fibre.

- With the increasing PVA fibre content, the initial and final setting time of SHGC mixtures was increased by $14.9 \%$ and $8.0 \%$ respectively due to the increased air voids with lower thermal conductivity. However, the setting time of SHGC decreased with the addition of RTS fibre due to the hydrophilic surface of RTS fibre, which absorbed water from the alkaline activator and thus accelerated the geopolymerisation process in SHGC.

- The 28-d drying shrinkage of SHGC mixtures was increased by $52.7 \%$ when increasing the PVA fibre content from $1.5 \mathrm{vol} \%$ to $2.0 \mathrm{vol} \%$ due to the weaker interaction between geopolymer matrix and oil-coated PVA fibre. However, replacing the PVA fibre by RTS fibre with levels of 0.25 vol\% and 0.5 vol\% resulted in the decrease of 28 -d drying shrinkage of SHGC by $62.0 \%$ and $72.5 \%$, respectively, which can be ascribed to the high elastic modulus of RTS fibre and the strong RTS fibre-matrix bond induced by its hydrophilic nature and large surface area.

- With the increase of PVA fibre content from $1.5 \mathrm{vol} \%$ to $2.0 \mathrm{vol} \%$, the 28 -d compressive strength of SHGC specimens was decreased by $7.3 \%$ due to the increased porosity, while it was 
significantly enhanced with the addition of RTS fibre because of the high stiffness and hydrophilic nature of RTS fibre, which can absorb more energy and provide strong fibre-matrix interaction.

- All SHGC mixtures exhibited deflection hardening behaviour under bending. The mono-PVA fibre reinforced SHGC had a high ductility with uniformly distributed microcracks, approximately $81.1 \%$ and $40.6 \%$ of which had a width of smaller than $60 \mu \mathrm{m}$ for SHGC with 1.5 vol $\%$ and 2.0 vol $\%$ PVA fibre, respectively. However, the ductility and crack widths were reduced with the inclusion of RTS fibre.

- The 28-d first-crack strength of SHGC was increased by about $13 \%$ with the increase of total fibre content from $1.5 \mathrm{vol} \%$ to $2.0 \mathrm{Vol} \%$ but decreased with the partial replacement of PVA fibre with RTS fibre as the fibre bridging effect was mainly provided by PVA fibre. The flexural toughness of SHGC was increased with both the addition and replacement of RTS fibre, while the post-crack toughness was found almost unchanged. The increase of PVA fibre content improved the postcrack toughness of SHGC as a result of the fibre bridging effect.

In this paper, the fresh and hardened properties of SHGC were studied and the emphasis was placed on flexural behaviour. In order to gain a comprehensive understanding of micromechanical properties and optimise the mix proportions of SHGC, it is vital to explore the fibre-matrix interaction and strain hardening behaviour through single fibre pull-out and uniaxial tension tests. This is a subject of ongoing work and will be presented in a future publication.

\section{Acknowledgement}

The authors gratefully acknowledge the financial support from the Engineering and Physical Sciences Research Council (EPSRC) under Grant No. EP/R041504/1 and the Royal Society under Award No. IEC \NSFC $\backslash 191417$. The authors would like to thank Twincon Ltd for generously providing recycled tyre fibres and Mr. Warren Gaynor, Dr. Shi Shi, and Mr. Raman Mangabhai for their help with experiments.

\section{References}

[1] Li VC, Wang SX, Wu C. Tensile strain-hardening behavior of polyvinyl alcohol engineered cementitious composite (PVA-ECC). ACI Mater J 2001;98(6):483-92.

[2] Li VC. On engineered cementitious composites (ECC) A review of the material and its applications. J Adv Concr Technol 2003;1(3):215-30.

[3] Rokugo K, Kanda T, Yokota H, Sakata N. Applications and recommendations of high performance 
fiber reinforced cement composites with multiple fine cracking (HPFRCC) in Japan. Mater Struct 2009;42:1197-208.

[4] Paulay T, Binney JR. Diagonally reinforced coupling beams of shear walls. ACI Symp Publ 1974;42:579-98.

[5] Kanakubo T, Kabele P, Fukuyama H, Uchida Y, Suwada H, Slowik V. Strain hardening cement composites: Structural design and performance State-of-the-art report of the RILEM technical committee 208-HFC, SC3. Springer Netherlands, 2013.

[6] Hassan A, Arif M, Shariq M. A review of properties and behaviour of reinforced geopolymer concrete structural elements- A clean technology option for sustainable development. J Clean Prod 2020;245:118762.

[7] Ding Y, Dai JG, Shi CJ. Mechanical properties of alkali-activated concrete: A state-of-the-art review. Constr Build Mater 2016;127:68-79.

[8] Jindal BB. Investigations on the properties of geopolymer mortar and concrete with mineral admixtures: A review. Constr Build Mater 2019;227:116644.

[9] Lehne J, Preston F. Making concrete change: Innovation in low-carbon cement and concrete. London: The Royal Institute of International Affairs, 2018.

[10] Provis JL, Van Deventer JSJ. Geopolymers: structures, processing, properties and industrial applications. Elsevier, 2009.

[11] Yang KH, Song JK, Song KI. Assessment of $\mathrm{CO}_{2}$ reduction of alkali-activated concrete. J Clean Prod 2013;39:265-72.

[12] Nematollahi B, Sanjayan J, Qiu J, Yang EH. Micromechanics-based investigation of a sustainable ambient temperature cured one-part strain hardening geopolymer composite. Constr Build Mater 2017;131:552-63.

[13] Shaikh FUA. Deflection hardening behaviour of short fibre reinforced fly ash based geopolymer composites. Mater Des 2013;50:674-82.

[14] Ohno M, Li VC. A feasibility study of strain hardening fiber reinforced fly ash-based geopolymer composites. Constr Build Mater 2014;57:163-8.

[15] Choi JI, Lee BY, Ranade R, Li VC, Lee Y. Ultra-high-ductile behavior of a polyethylene fiberreinforced alkali-activated slag-based composite. Cem Concr Compos 2016;70:153-8.

[16] Kumar S, Kumar R, Mehrotra SP. Influence of granulated blast furnace slag on the reaction, 
structure and properties of fly ash based geopolymer. J Mater Sci 2010;45:607-15.

[17] Somna K, Jaturapitakkul C, Kajitvichyanukul P, Chindaprasirt P. NaOH-activated ground fly ash geopolymer cured at ambient temperature. Fuel 2011;90(6):2118-24.

[18] Fang G, Ho WK, Tu W, Zhang M. Workability and mechanical properties of alkali-activated fly ash-slag concrete cured at ambient temperature. Constr Build Mater 2018;172:476-87.

[19] Shaikh FUA, Fairchild A, Zammar R. Comparative strain and deflection hardening behaviour of polyethylene fibre reinforced ambient air and heat cured geopolymer composites. Constr Build Mater 2018;163:890-900.

[20] Ling Y, Wang K, Li W, Shi G, Lu P. Effect of slag on the mechanical properties and bond strength of fly ash-based engineered geopolymer composites. Compos B Eng 2019;164:747-57.

[21] Singh M, Saini B, Chalak HD. Performance and composition analysis of engineered cementitious composite (ECC) - A review. J Build Eng 2019;26:100851.

[22] Maalej M, Quek ST, Ahmed SFU, Zhang J, Lin VWJ, Leong KS. Review of potential structural applications of hybrid fiber Engineered Cementitious Composites. Constr Build Mater 2012;36:21627.

[23] Soe KT, Zhang YX, Zhang LC. Material properties of a new hybrid fibre-reinforced engineered cementitious composite. Constr Build Mater 2013;43:399-407.

[24] Ranjbar N, Zhang M. Fiber-reinforced geopolymer composites: A review. Cem Concr Compos 2020;107:103498.

[25] Pakravan HR, Jamshidi M, Latifi M. Study on fiber hybridisation effect of engineered cementitious composites with low- and high-modulus polymeric fibers. Constr Build Mater 2016;112:739-46.

[26] Li VC, Wu HC, Maalej M, Mishra DK, Hashida T. Tensile behavior of cement-based composites with random discontinuous steel fibers. J Am Ceram Soc 1996;79(1):74-8.

[27] Farooq M, Bhutta A, Banthia N. Tensile performance of eco-friendly ductile geopolymer composites (EDGC) incorporating different micro-fibers. Cem Concr Compos 2019;103:183-92.

[28] Mohammed BS, Khed VC, Liew MS. Optimization of hybrid fibres in engineered cementitious composites. Constr Build Mater 2018;190:24-37.

[29] Wang Q, Yi Y, Ma G, Luo H. Hybrid effects of steel fibers, basalt fibers and calcium sulfate on mechanical performance of PVA-ECC containing high-volume fly ash. Cem Concr Compos 
2019;97:357-68.

[30] Li Q, Zhao X, Xu S, Leung CKY, Wang B. Multiple impact resistance of hybrid fiber ultrahigh toughness cementitious composites with different degrees of initial damage. J Mater Civil Eng 2019;31(2):04018368.

[31] Yu J, Chen Y, Leung CKY. Micromechanical modeling of crack-bridging relations of hybridfiber Strain-Hardening Cementitious Composites considering interaction between different fibers. Constr Build Mater 2018;182:629-36.

[32] Liew KM, Akbar A. The recent progress of recycled steel fiber reinforced concrete. Constr Build Mater 2020;232:117232.

[33] Ramarad S, Khalid M, Ratnam CT, Chuah AL, Rashmi W. Waste tire rubber in polymer blends: A review on the evolution, properties and future. Prog Mater Sci 2015;72:100-40.

[34] Gigli S, Landi D, Germani M. Cost-benefit analysis of a circular economy project: a study on a recycling system for end-of-life tyres. J Clean Prod 2019;229:680-94.

[35] Domski J, Katzer J, Zakrzewski M, Ponikiewski T. Comparison of the mechanical characteristics of engineered and waste steel fiber used as reinforcement for concrete. J Clean Prod 2017;158:18-28. [36] Aghaee K, Yazdi MA, Tsavdaridis KD. Investigation into the mechanical properties of structural lightweight concrete reinforced with waste steel wires. Mag Concr Res 2015;67(4):197-205.

[37] Martinelli E, Caggiano A, Xargay H. An experimental study on the post-cracking behaviour of hybrid industrial/recycled steel fibre-reinforced concrete. Constr Build Mater 2015;94:290-8.

[38] Leone M, Centonze G, Colonna D, Micelli F, Aiello MA. Fiber-reinforced concrete with low content of recycled steel fiber: Shear behaviour. Constr Build Mater 2018;161:141-55.

[39] Zamanzadeh Z, Lourenço L, Barros J. Recycled steel fibre reinforced concrete failing in bending and in shear. Constr Build Mater 2015;85:195-207.

[40] Zhong H, Zhang M. Experimental study on engineering properties of concrete reinforced with hybrid recycled tyre steel and polypropylene fibres. J Clean Prod 2020;259:120914.

[41] ASTM C618. Standard specification for coal fly ash and raw or calcined ntural pozzolan for use in concrete. Philadelphia: ASTM International; 2017.

[42] Nematollahi B, Sanjayan J. Effect of different superplasticisers and activator combinations on workability and strength of fly ash based geopolymer. Mater Des 2014;57:667-72.

[43] Li VC, Wu C, Wang SX, Ogawa A, Saito T. Interface tailoring for strain-hardening polyvinyl 
alcohol-engineered cementitious composite (PVA-ECC). ACI Mater J 2002;99(5):463-72.

[44] Wang Y, Wang Y, Zhang M. Effect of micro-silica sand on engineering properties of strain hardening geopolymer composites (under review). J Build Eng 2020.

[45] ASTM C1437. Standard test method for flow of hydraulic cement mortar. Philadelphia: ASTM International; 2015.

[46] ASTM C191. Standard test methods for time of setting of hydraulic cement by vicat needle. Philadelphia: ASTM International; 2008.

[47] ASTM C490. Standard practice for use of apparatus for the determination of length change of hardened cement paste, mortar, and concrete. Philadelphia: ASTM International; 2017.

[48] ASTM C109. Standard test method for compressive strength of hydraulic cement mortars (using 2-in. or [50-mm] cube specimens). Philadelphia: ASTM International; 2020.

[49] ASTM C1609. Standard Test Method for Flexural Performance of Fiber-Reinforced Concrete (Using Beam With Third-Point Loading). Philadelphia: ASTM International; 2005.

[50] Noushini A, Hastings M, Castel A, Aslani F. Mechanical and flexural performance of synthetic fibre reinforced geopolymer concrete. Constr Build Mater 2018;186:454-75.

[51] ASTM C1018. Standard test method for flexural toughness first-crack strength of fiberreinforced concrete. Philadelphia: ASTM International; 1998.

[52] Masi G, Rickard WDA, Bignozzi MC, van Riessen A. The effect of organic and inorganic fibres on the mechanical and thermal properties of aluminate activated geopolymers. Compos B Eng 2015;76:218-28.

[53] Zhong H, Poon EW, Chen K, Zhang M. Engineering properties of crumb rubber alkali-activated mortar reinforced with recycled steel fibres. J Clean Prod 2020;238:117950.

[54] Pakravan HR, Ozbakkaloglu T. Synthetic fibers for cementitious composites: A critical and indepth review of recent advances. Constr Build Mater 2019;207:491-518.

[55] Farhan AH, Dawson AR, Thom NH. Recycled hybrid fiber-reinforced \& cement-stabilised pavement mixtures: Tensile properties and cracking characterisation. Constr Build Mater 2018;179:488-99.

[56] Farhan NA, Sheikh MN, Hadi MNS. Engineering properties of ambient cured alkali-activated fly ash-slag concrete reinforced with different types of steel fiber. J Mater Civ Eng 2018;30(7):04018142. 
[57] Martinie L, Rossi P, Roussel N. Rheology of fiber reinforced cementitious materials: classification and prediction. Cem Concr Res 2010;40(2):226-34.

[58] Sengul O. Mechanical behavior of concretes containing waste steel fibers recovered from scrap tires. Constr Build Mater 2016;122:649-58.

[59] Huseien GF, Ismail M, Khalid NHA, Hussin MW, Mirza J. Compressive strength and microstructure of assorted wastes incorporated geopolymer mortars: Effect of solution molarity. Alex Eng J 2018;57(4):3375-86.

[60] Nath P, Sarker PK. Effect of GGBFS on setting, workability and early strength properties of fly ash geopolymer concrete cured in ambient condition. Constr Build Mater 2014;66:163-71.

[61] Siyal AA, Azizli KA, Man Z, Ullah H. Effects of parameters on the setting time of fly ash based geopolymers using taguchi method. Procedia Eng 2016;148:302-7.

[62] Fang G, Bahrami H, Zhang M. Mechanisms of autogenous shrinkage of alkali-activated fly ashslag pastes cured at ambient temperature within $24 \mathrm{~h}$. Constr Build Mater 2018;171:377-87.

[63] Temuujin J, van Riessen A, MacKenzie KJD. Preparation and characterisation of fly ash based geopolymer mortars. Constr Build Mater 2010;24(10):1906-10.

[64] Yang T, Zhu H, Zhang Z. Influence of fly ash on the pore structure and shrinkage characteristics of metakaolin-based geopolymer pastes and mortars. Constr Build Mater 2017;153:284-93.

[65] Bernal S, De Gutierrez R, Delvasto S, Rodriguez E. Performance of an alkali-activated slag concrete reinforced with steel fibers. Constr Build Mater 2010;24(2):208-14.

[66] Ranjbar N, Talebian S, Mehrali M, Kuenzel C, Metselaar HSC, Jumaat MZ. Mechanisms of interfacial bond in steel and polypropylene fiber reinforced geopolymer composites. Compos Sci Technol 2016;122:73-81.

[67] Afroughsabet V, Teng S. Experiments on drying shrinkage and creep of high performance hybridfiber-reinforced concrete. Cem Concr Compos 2020;106:103481.

[68] Ranjbar N, Mehrali M, Mehrali M, Alengaram UJ, Jumaat MZ. High tensile strength fly ash based geopolymer composite using copper coated micro steel fiber. Constr Build Mater 2016;112:629-38.

[69] Jenq YS, Shah SP. Crack propagation in fiber-reinforced concrete. J Struct Eng 1986;112(1):1934.

[70] Fang G, Zhang M. Multiscale micromechanical analysis of alkali-activated fly ash-slag paste. 
Cem Concr Res 2020;135:106141.

[71] van Zijl GPAG, Slowik V. A framework for durability design with strain-hardening cement-based composites (SHCC): State-of-the-art report of the RILEM technical committee 240-FDS. Springer Netherlands, 2017.

[72] Nematollahi B, Sanjayan J, Shaikh FUA. Tensile strain hardening behavior of PVA fiberreinforced engineered geopolymer composite. J Mater Civ Eng 2015;27(10):04015001.

[73] Sukontasukkul P, Pongsopha P, Chindaprasirt P, Songpiriyakij S. Flexural performance and toughness of hybrid steel and polypropylene fibre reinforced geopolymer. Constr Build Mater 2018;161:37-44. 
Table 1. Chemical compositions (wt $\%$ ) of fly ash (FA) and slag (GGBS).

\begin{tabular}{lllllllllll}
\hline Oxide & $\mathrm{SiO}_{2}$ & $\mathrm{Al}_{2} \mathrm{O}_{3}$ & $\mathrm{CaO}$ & $\mathrm{MgO}$ & $\mathrm{K}_{2} \mathrm{O}$ & $\mathrm{Fe}_{2} \mathrm{O}_{3}$ & $\mathrm{TiO}_{2}$ & $\mathrm{Na}_{2} \mathrm{O}$ & $\mathrm{SO}_{3}$ & $\mathrm{LOI}$ \\
\hline FA & 49.80 & 25.08 & 4.65 & 1.67 & 3.30 & 11.67 & 1.24 & 0.66 & 1.35 & 0.58 \\
GGBS & 36.77 & 13.56 & 37.60 & 7.45 & 0.55 & 0.41 & 0.79 & 0.25 & 1.82 & 0.80 \\
\hline
\end{tabular}

Note: LOI (loss on ignition).

Table 2. Properties of superplasticisers (SPs).

\begin{tabular}{llll}
\hline $\begin{array}{l}\text { Specific gravity } \\
\left(25^{\circ} \mathrm{C}\right)\end{array}$ & $\mathrm{pH}\left(25^{\circ} \mathrm{C}\right)$ & $\begin{array}{l}\text { Content of chloride ion } \\
(\%)\end{array}$ & $\begin{array}{l}\text { Content of alkaline } \\
(\%)\end{array}$ \\
\hline 1.08 & $4-5$ & $\leq 0.1$ & $\leq 0.4$ \\
\hline
\end{tabular}

Table 3. Technical properties of fibres used in this study.

\begin{tabular}{lllllll}
\hline $\begin{array}{l}\text { Fibre } \\
\text { ID }\end{array}$ & $\begin{array}{l}\text { Length } \\
(\mathrm{mm})\end{array}$ & $\begin{array}{l}\text { Nominal } \\
\text { diameter }(\mu \mathrm{m})\end{array}$ & $\begin{array}{l}\text { Aspect } \\
\text { ratio }\end{array}$ & $\begin{array}{l}\text { Density } \\
\left(\mathrm{g} / \mathrm{cm}^{3}\right)\end{array}$ & $\begin{array}{l}\text { Tensile } \\
\text { strength }(\mathrm{MPa})\end{array}$ & $\begin{array}{l}\text { Young's } \\
\text { modulus }(\mathrm{GPa})\end{array}$ \\
\hline PVA & 12 & 40 & 300 & 1.3 & 1600 & 41 \\
RTS & 20 & 150 & 133 & 7.8 & 2850 & 200 \\
\hline
\end{tabular}

Note: PVA (polyvinyl alcohol); RTS (recycled tyre steel).

Table 4. Mix proportions of strain hardening geopolymer composite (SHGC).

\begin{tabular}{|c|c|c|c|c|c|c|c|}
\hline \multirow{2}{*}{ Mix no. } & \multicolumn{2}{|c|}{ Binder } & \multirow{2}{*}{ Activator/binder } & \multirow{2}{*}{ Sand/binder } & \multirow{2}{*}{ SPs/binder } & \multirow{2}{*}{$\begin{array}{l}\text { PVA } \\
\text { (vol\%) }\end{array}$} & \multirow{2}{*}{$\begin{array}{l}\text { RTS } \\
\text { (vol\%) }\end{array}$} \\
\hline & FA & GGBS & & & & & \\
\hline M1 (P1.5) & 0.8 & 0.2 & 0.4 & 0.2 & 0.01 & 1.5 & 0 \\
\hline M2 (P2.0) & 0.8 & 0.2 & 0.4 & 0.2 & 0.01 & 2.0 & 0 \\
\hline M3 (P1.75S0.25) & 0.8 & 0.2 & 0.4 & 0.2 & 0.01 & 1.75 & 0.25 \\
\hline M4 (P1.5S0.5) & 0.8 & 0.2 & 0.4 & 0.2 & 0.01 & 1.5 & 0.5 \\
\hline
\end{tabular}

Table 5. Flexural properties of SHGC specimens.

\begin{tabular}{|c|c|c|c|c|c|c|c|c|c|c|}
\hline \multirow{2}{*}{ Mix no. } & \multicolumn{2}{|c|}{$D_{f 1}(\mathrm{~mm})$} & \multicolumn{2}{|c|}{$D_{f}(\mathrm{~mm})$} & \multicolumn{2}{|l|}{$D I$} & \multicolumn{2}{|c|}{$T_{f}(\mathrm{~J})$} & \multirow{2}{*}{$\frac{N}{28 \mathrm{~d}}$} & \multirow{2}{*}{$\begin{array}{l}W(\mu \mathrm{m}) \\
28 \mathrm{~d}\end{array}$} \\
\hline & $7 \mathrm{~d}$ & $28 \mathrm{~d}$ & $7 \mathrm{~d}$ & $28 \mathrm{~d}$ & $7 \mathrm{~d}$ & $28 \mathrm{~d}$ & $7 \mathrm{~d}$ & $28 \mathrm{~d}$ & & \\
\hline M1 (P1.5) & 0.69 & 0.65 & 24.19 & 18.39 & 38.78 & 28.58 & 0.70 & 0.73 & 106 & 36.96 \\
\hline M2 (P2.0) & 0.52 & 0.71 & 31.39 & 24.80 & 61.96 & 36.12 & 0.72 & 0.85 & 99 & 80.01 \\
\hline M3 (P1.75S0.25) & 0.59 & 0.74 & 19.19 & 15.82 & 32.62 & 21.39 & 0.75 & 0.83 & 146 & 29.83 \\
\hline M4 (P1.5S0.5) & 0.73 & 0.75 & 17.28 & 14.24 & 23.92 & 18.93 & 0.80 & 0.84 & 141 & 21.64 \\
\hline
\end{tabular}

Note: $D_{f 1}, D_{f}, D I$ and $T_{f}$ represent the first-crack deflection, ultimate flexural deflection, ductility index and flexural toughness of the specimens, respectively. $N$ and $W$ denote the crack number and crack width of the specimens, respectively. 


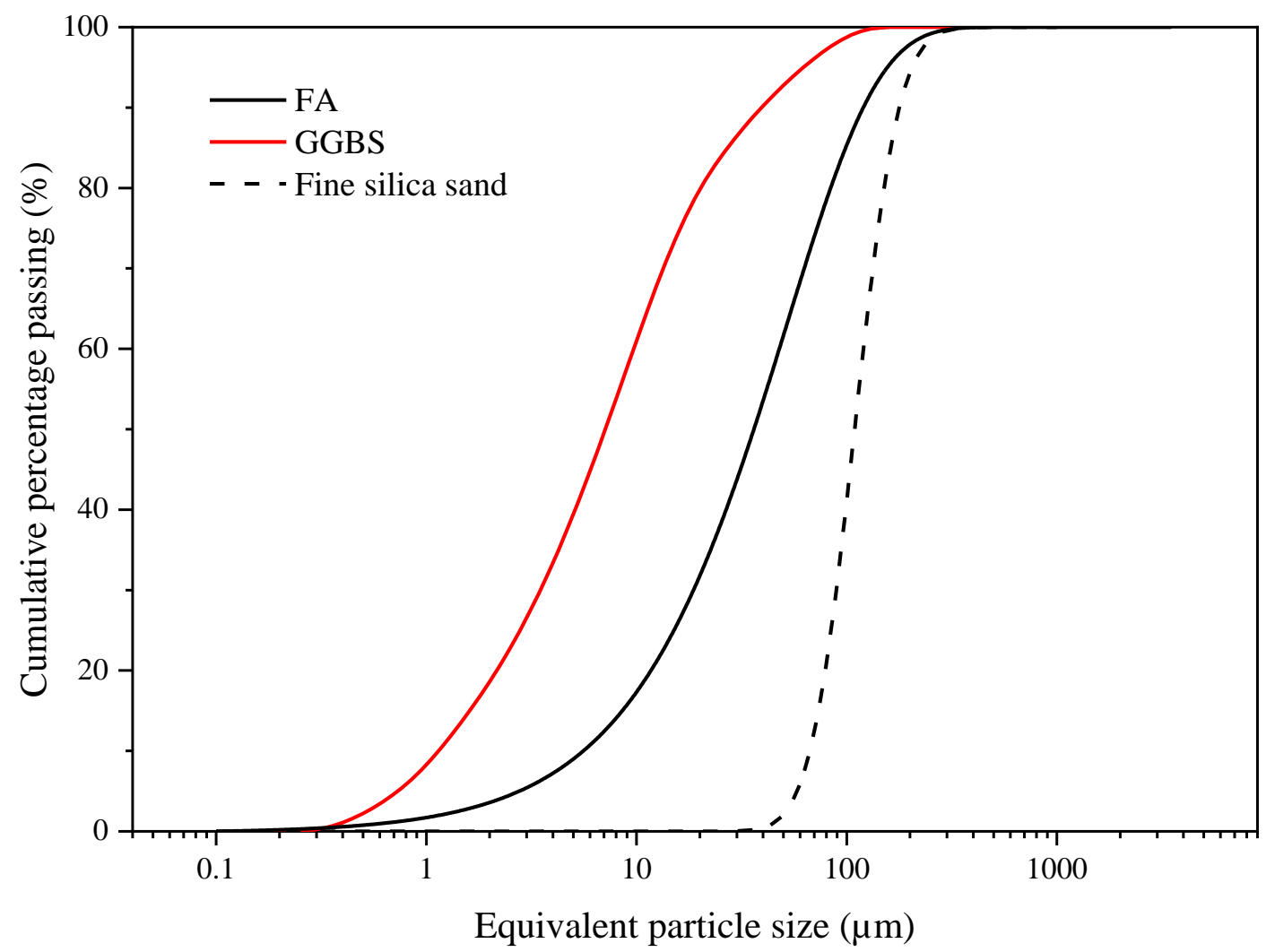

Fig. 1. Particle size distribution of FA, GGBS and fine silica sand.
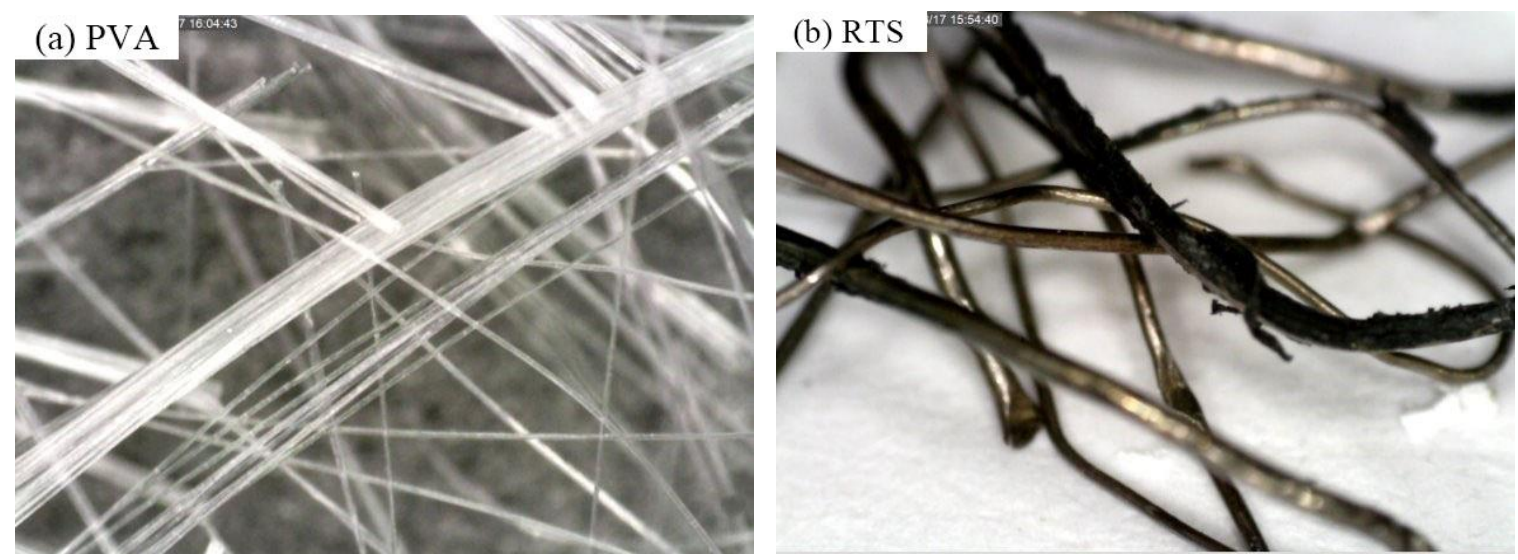

Fig. 2. Fibres used in this study: (a) PVA fibre; (b) RTS fibre. Images taken by digital microscope (Dino-Lite Edge AM73115MZT). 


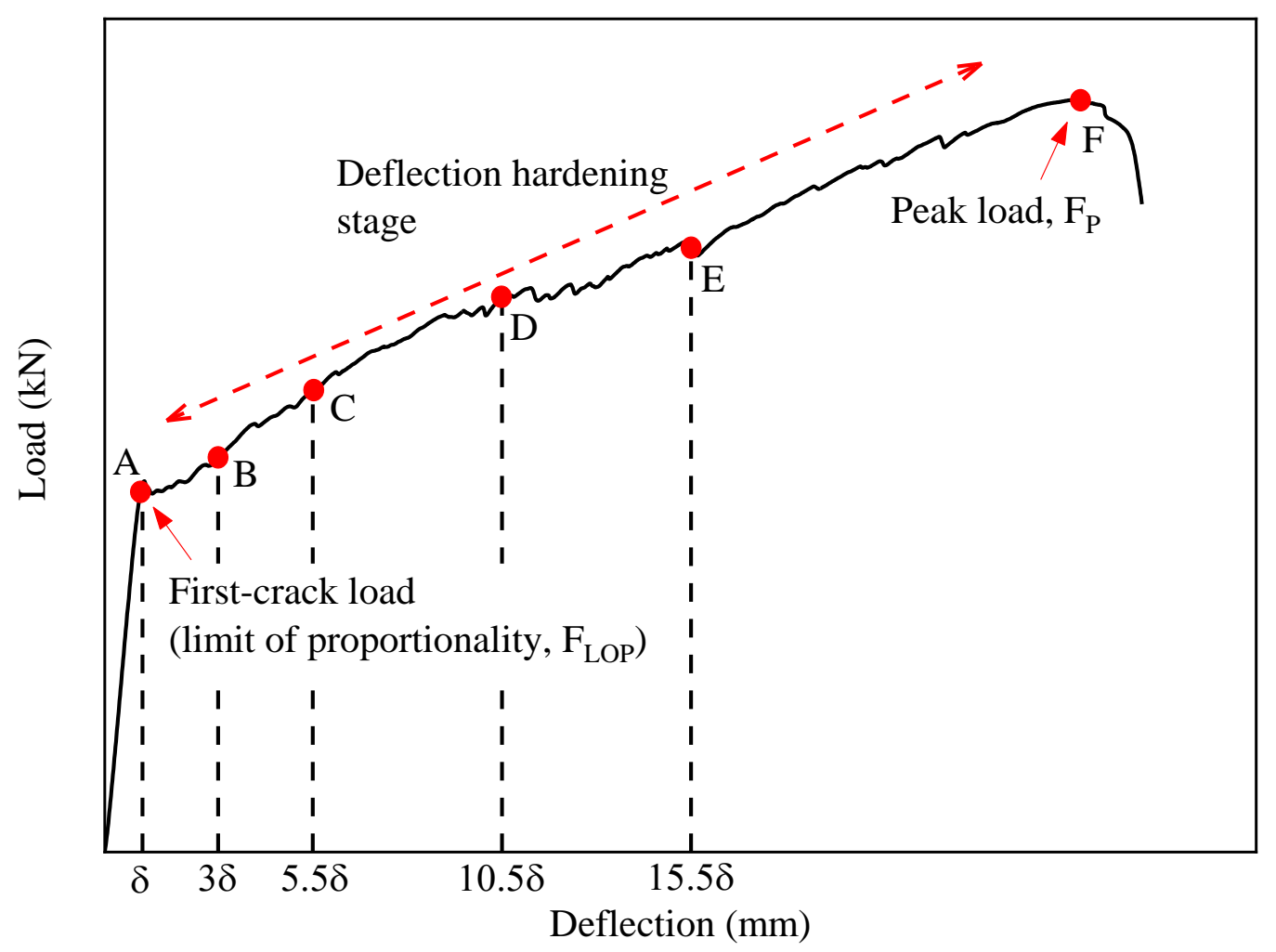

Fig. 3. Typical load-deflection curve for SHGC under bending.

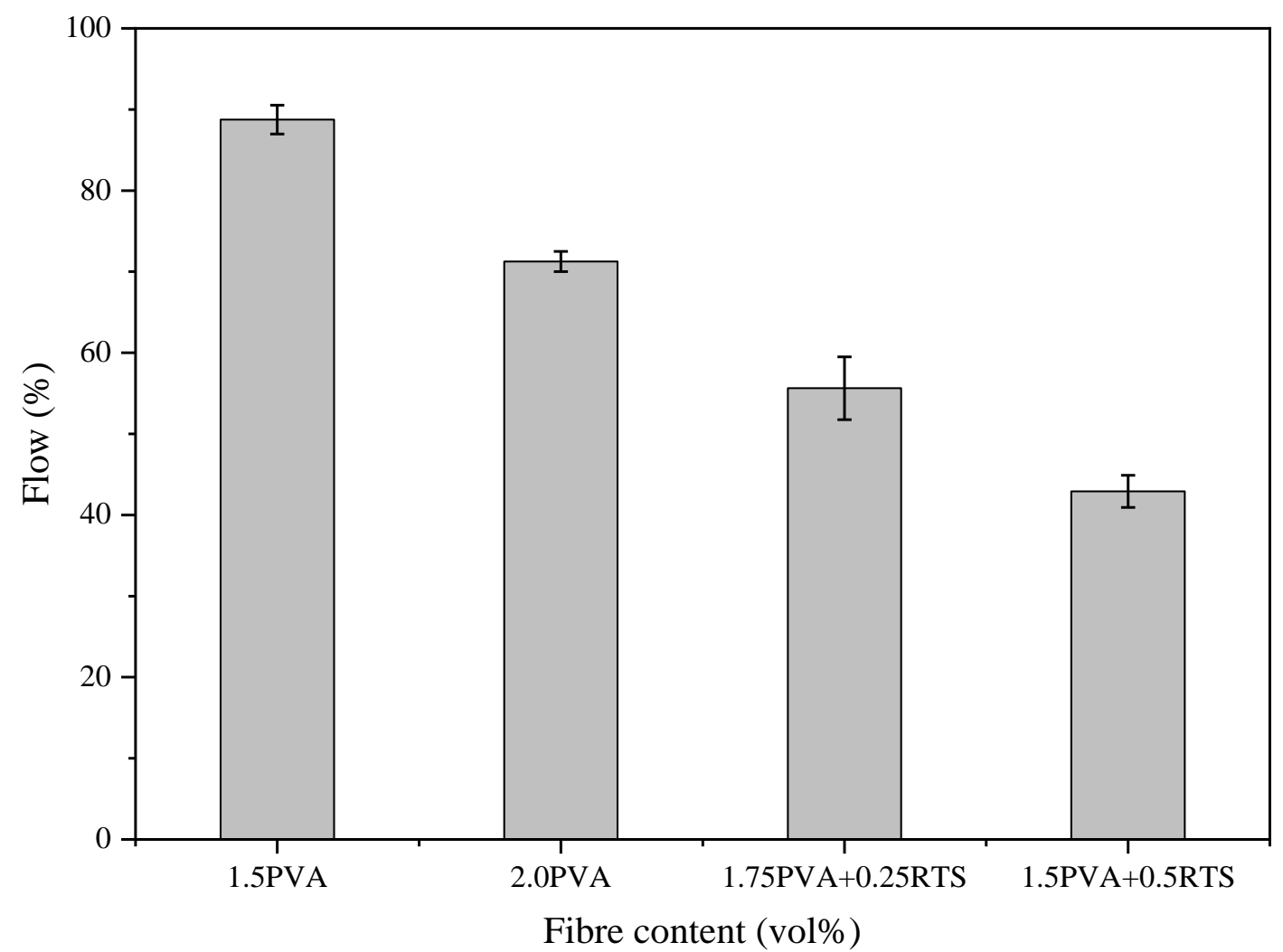

Fig.4. Flowability of fresh SHGC specimens with various hybrid fibre content. 


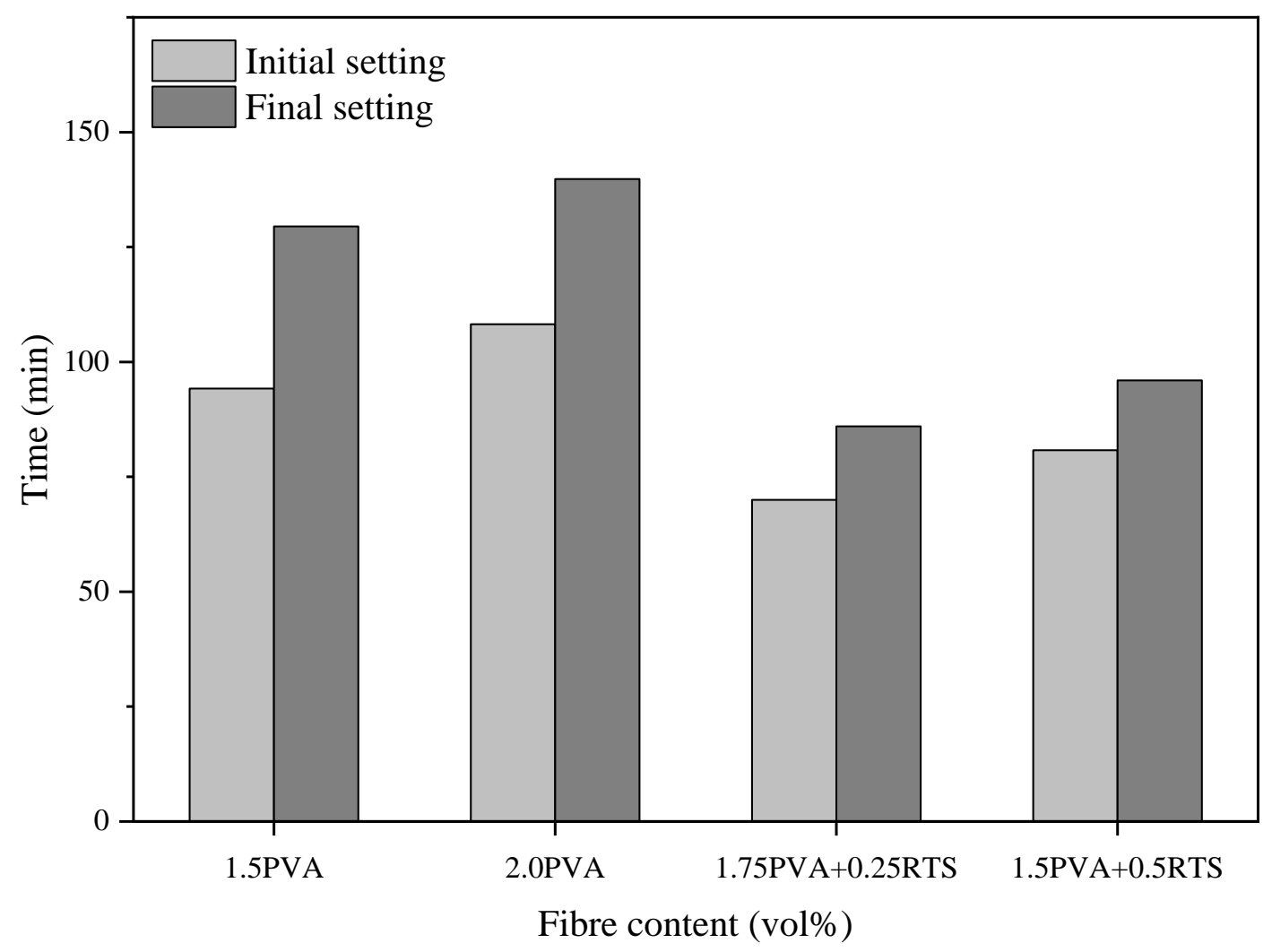

Fig. 5. Setting time of SHGC specimens with various hybrid fibre content.

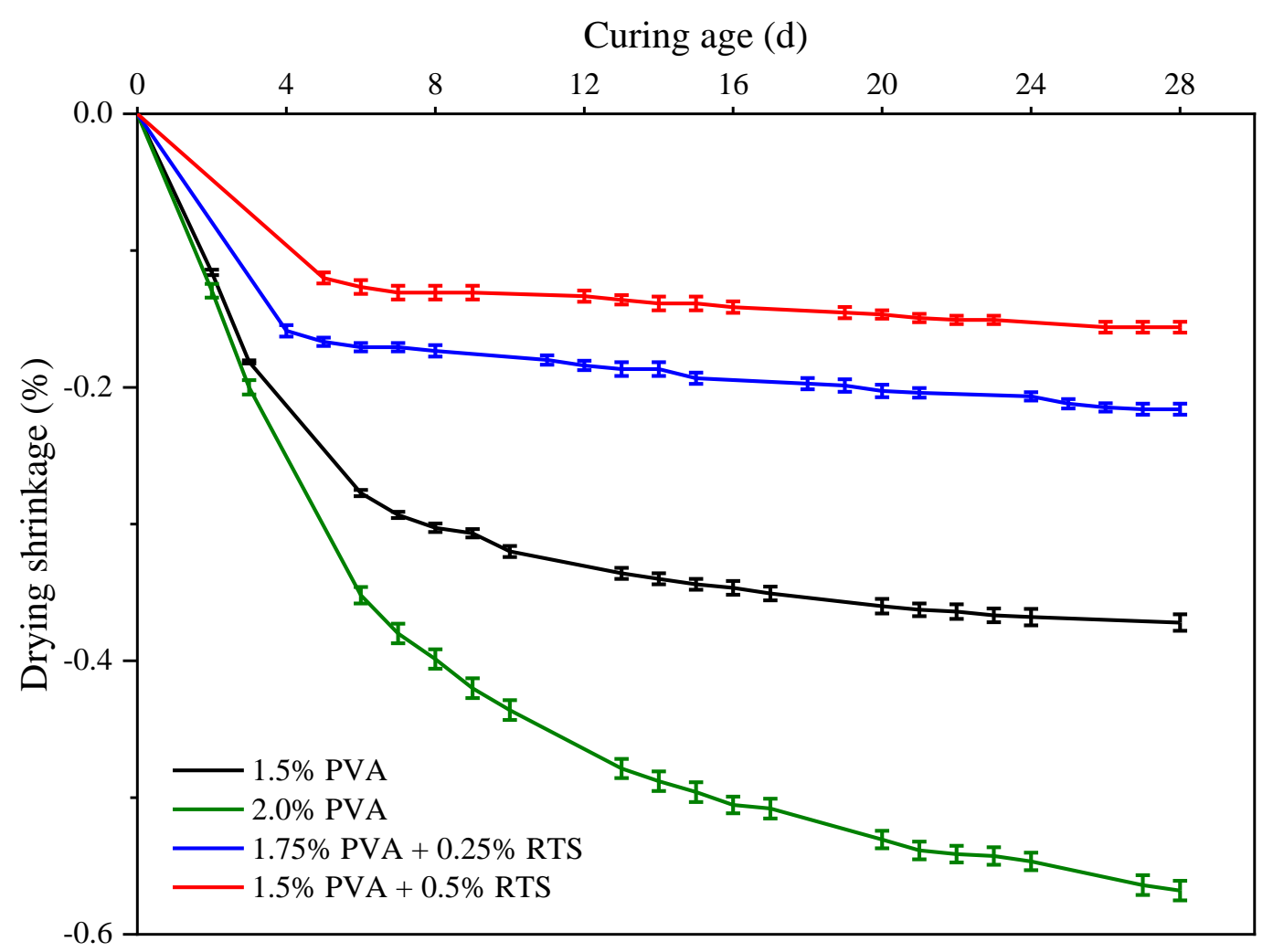

Fig. 6. Drying shrinkage of SHGC specimens with various hybrid fibre content. 


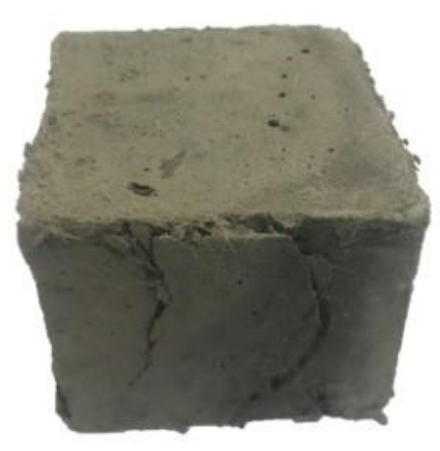

(a)

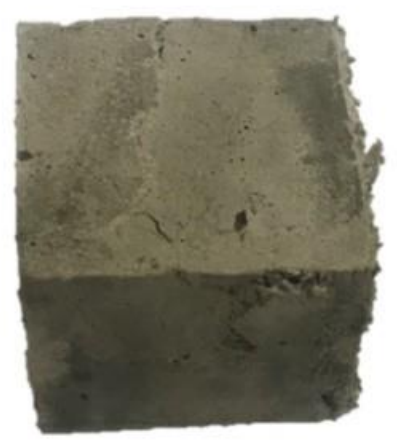

(c)

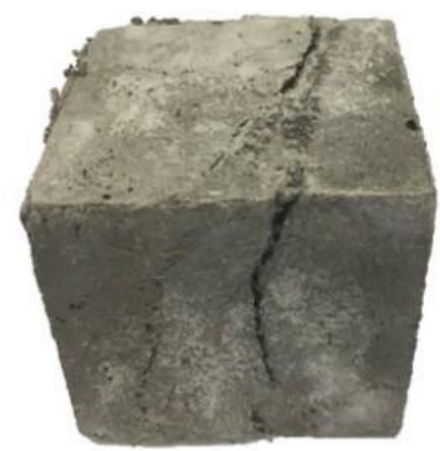

(b)

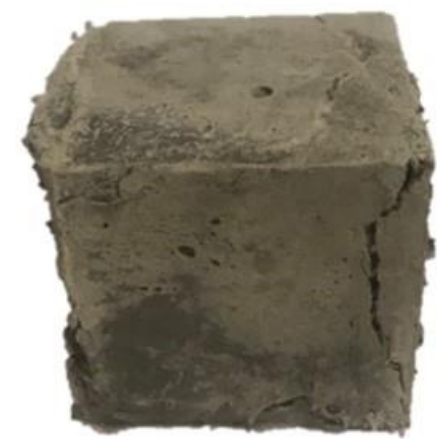

(d)

Fig. 7. Typical failure modes of specimens at $28 \mathrm{~d}$ : (a) M1 (P1.5); (b) M2 (P2.0); (c) M3 (P1.75S0.25); (d) M4 (P1.5S0.5).

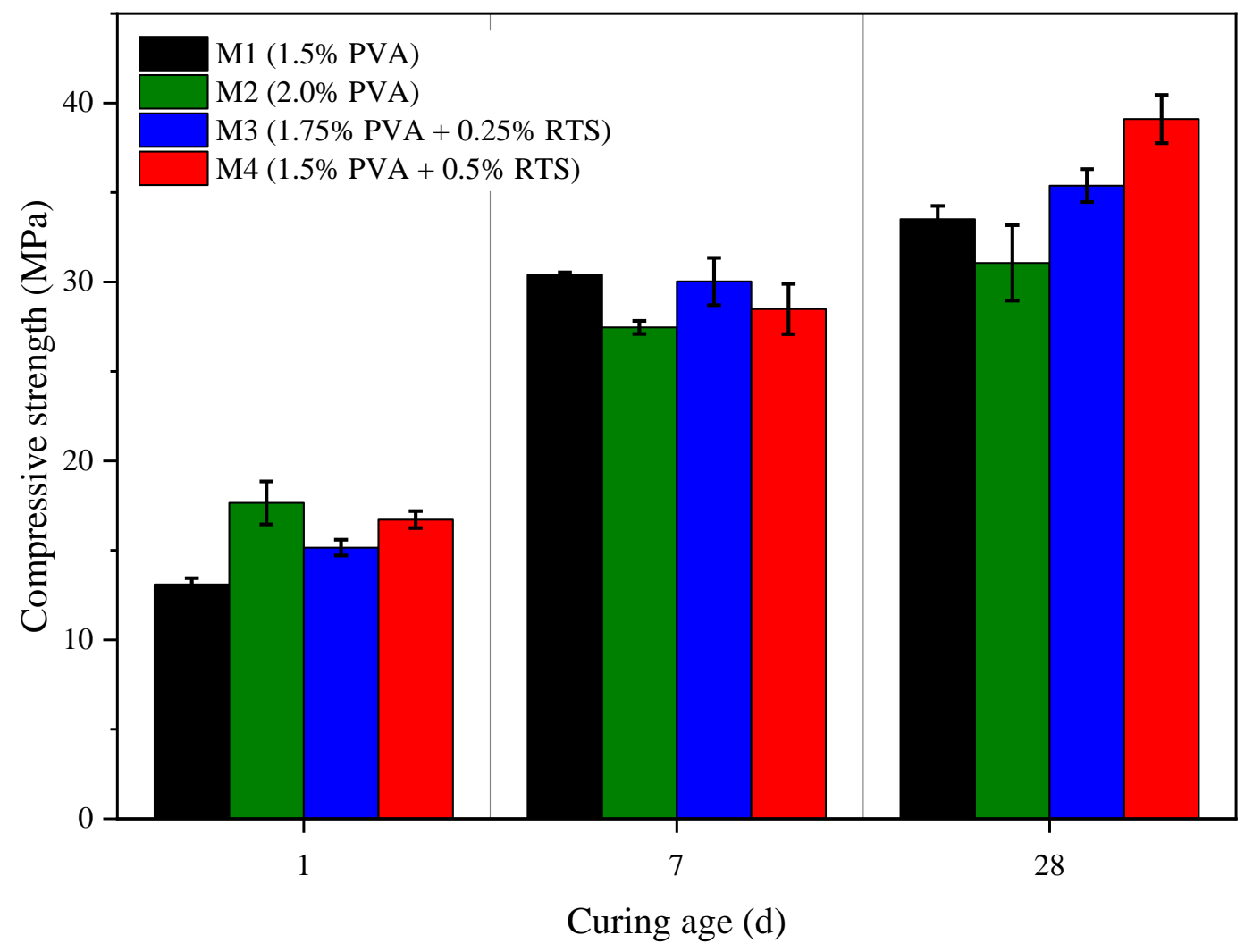

Fig. 8. Compressive strength of SHGC specimens with various hybrid fibre content. 

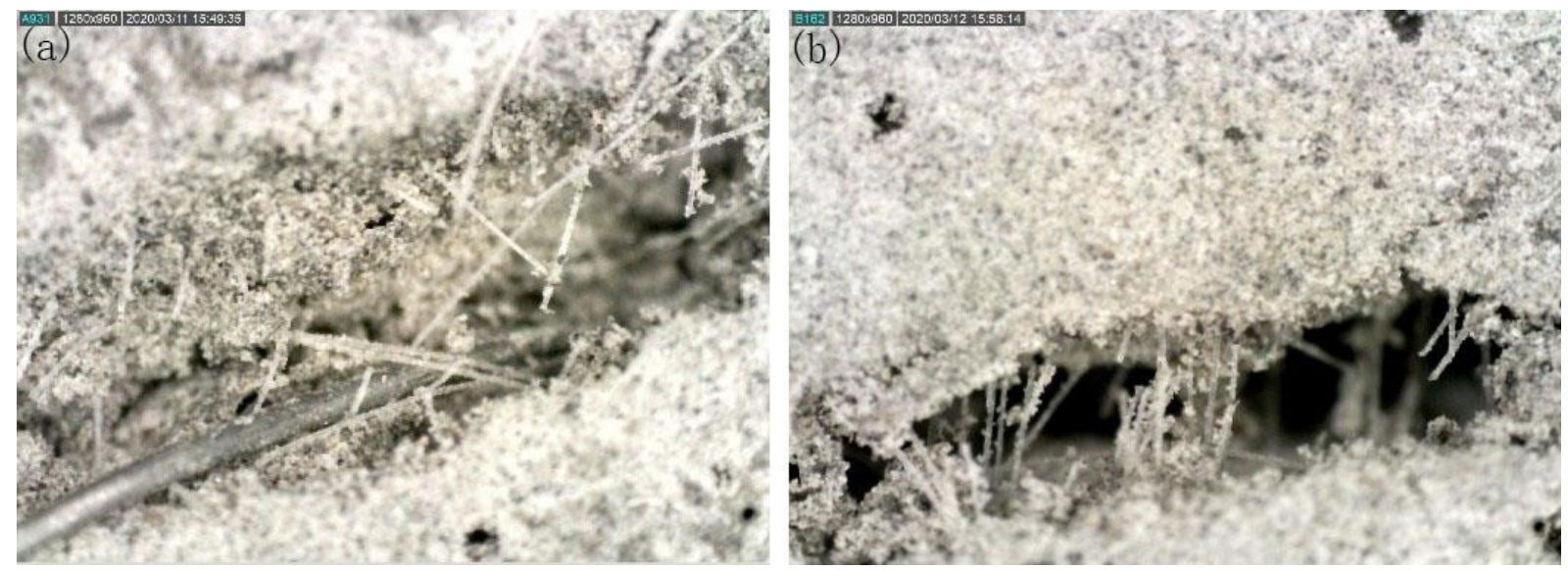

Fig. 9. Fibres in SHGC specimens subjected to compression: (a) Orientation of RTS and PVA fibres; (b) Distribution of PVA fibre.
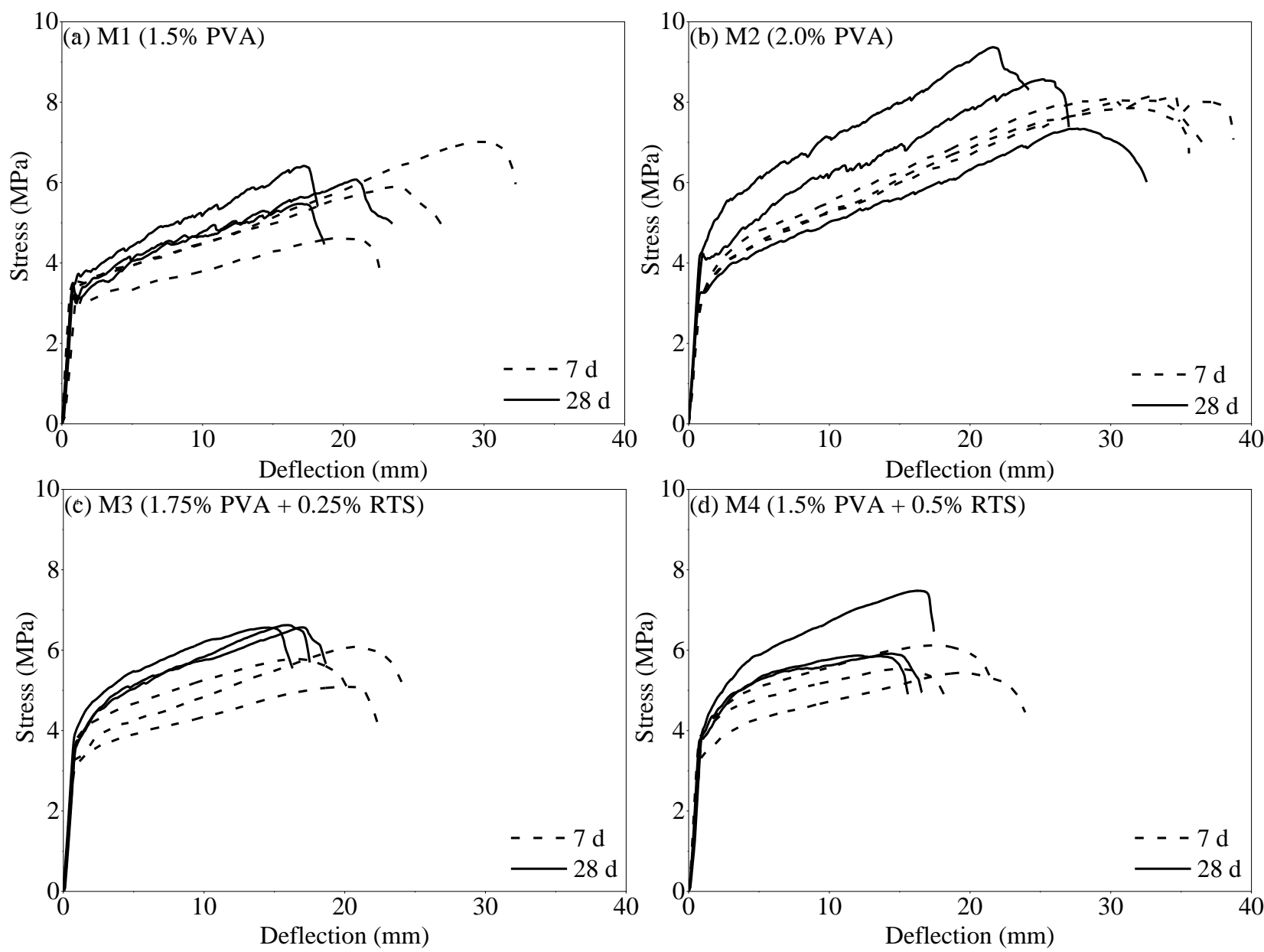

Fig. 10. Stress-deflection curves of SHGC specimens at $7 \mathrm{~d}$ and $28 \mathrm{~d}$ under four-point bending. 


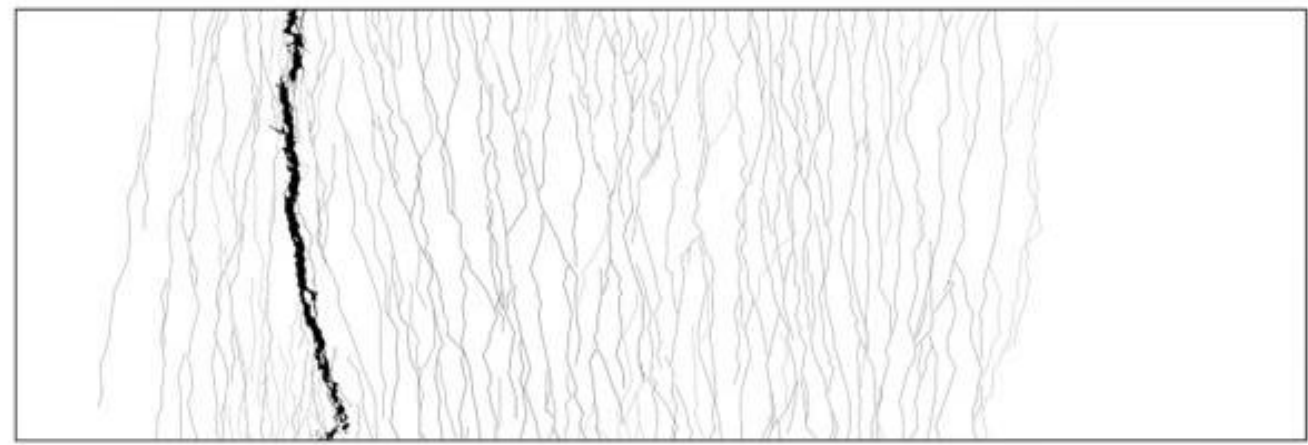

(a) M1 (P1.5)

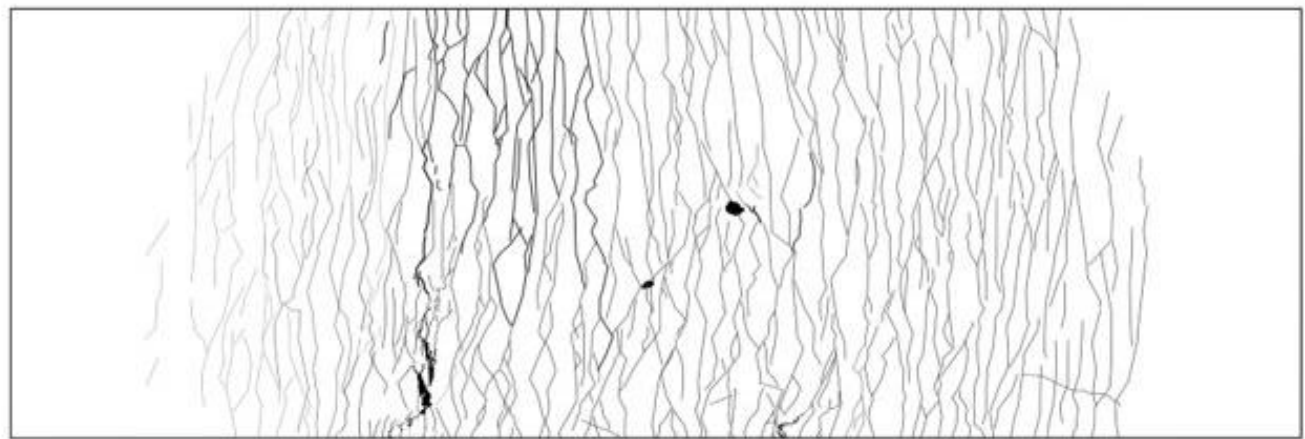

(b) M2 (P2.0)

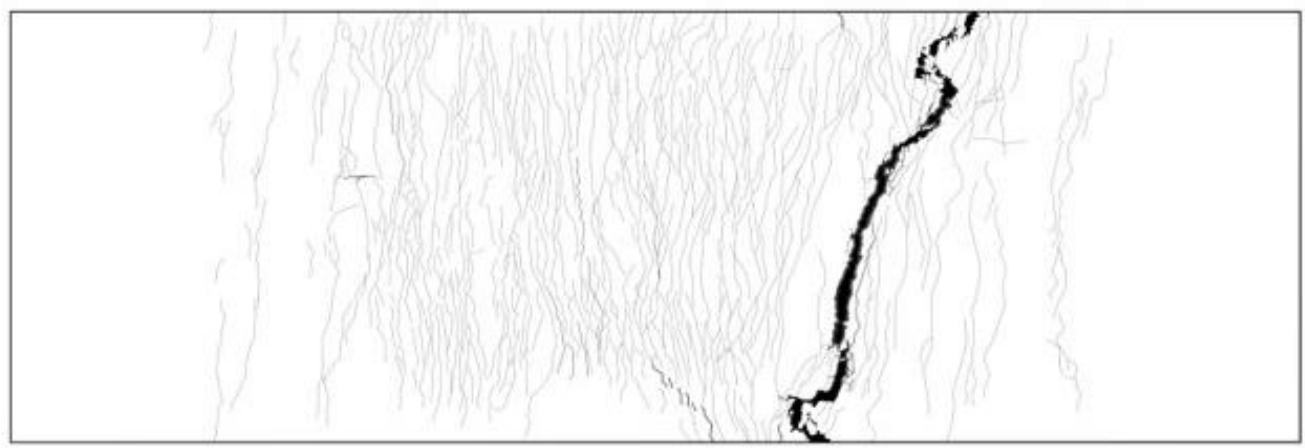

(c) M3 (P1.75S0.25)

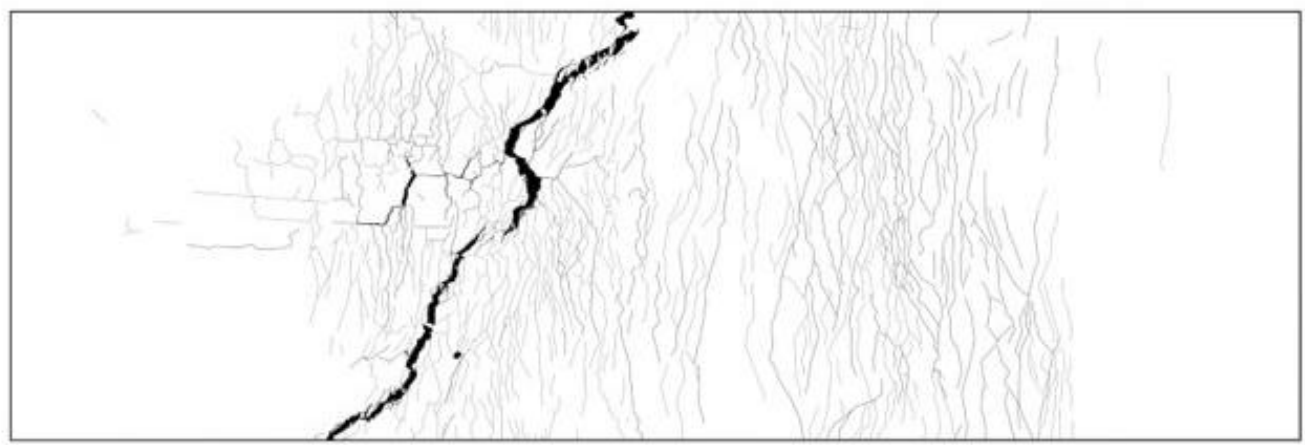

(d) M4 (P1.5S0.5)

Fig. 11. Typical crack patterns on the bottom surface of all mixtures at failure at $28 \mathrm{~d}$. 


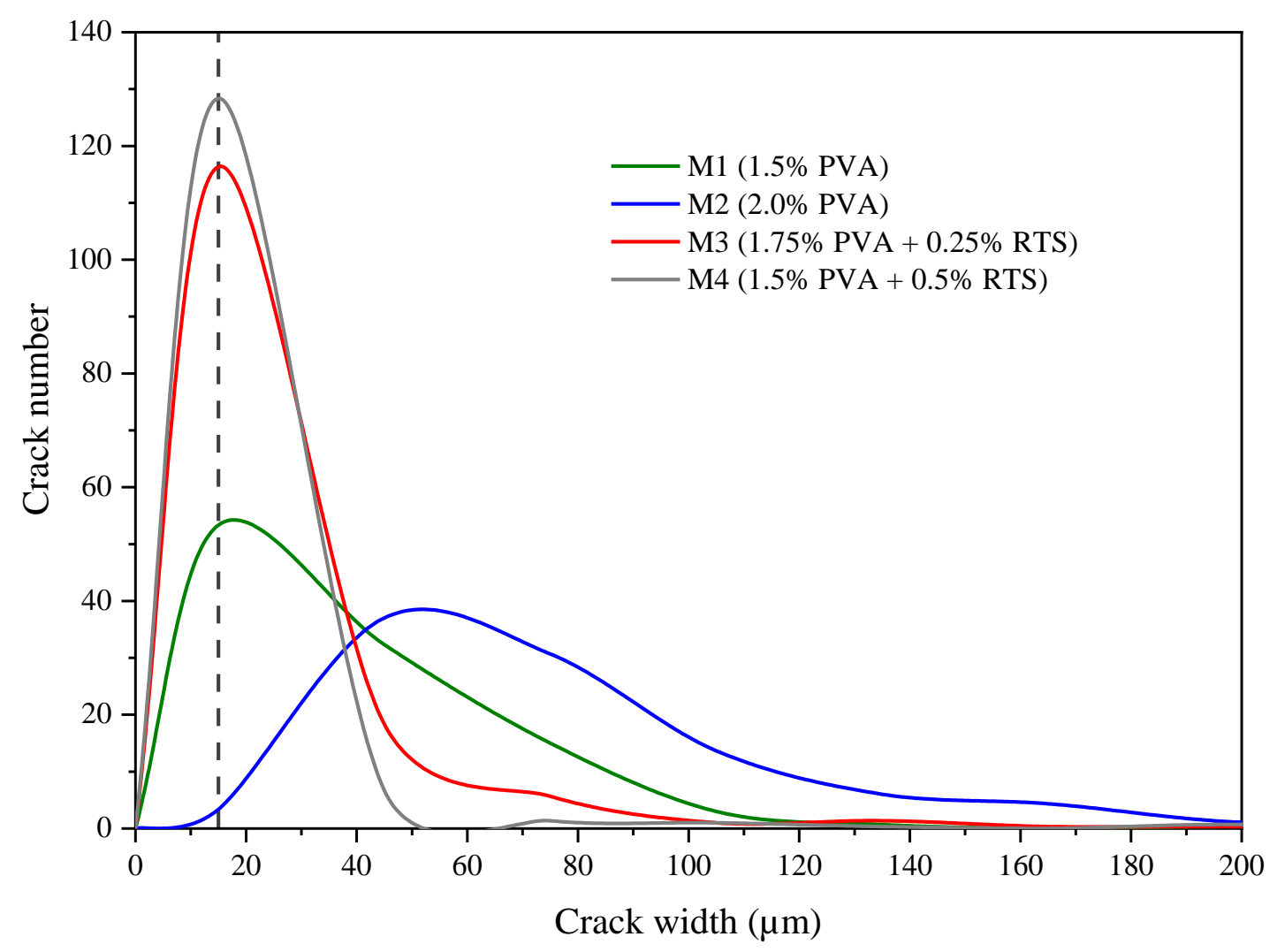

Fig. 12. Crack number and crack width of SHGC specimens with various hybrid fibre content at 28 d.
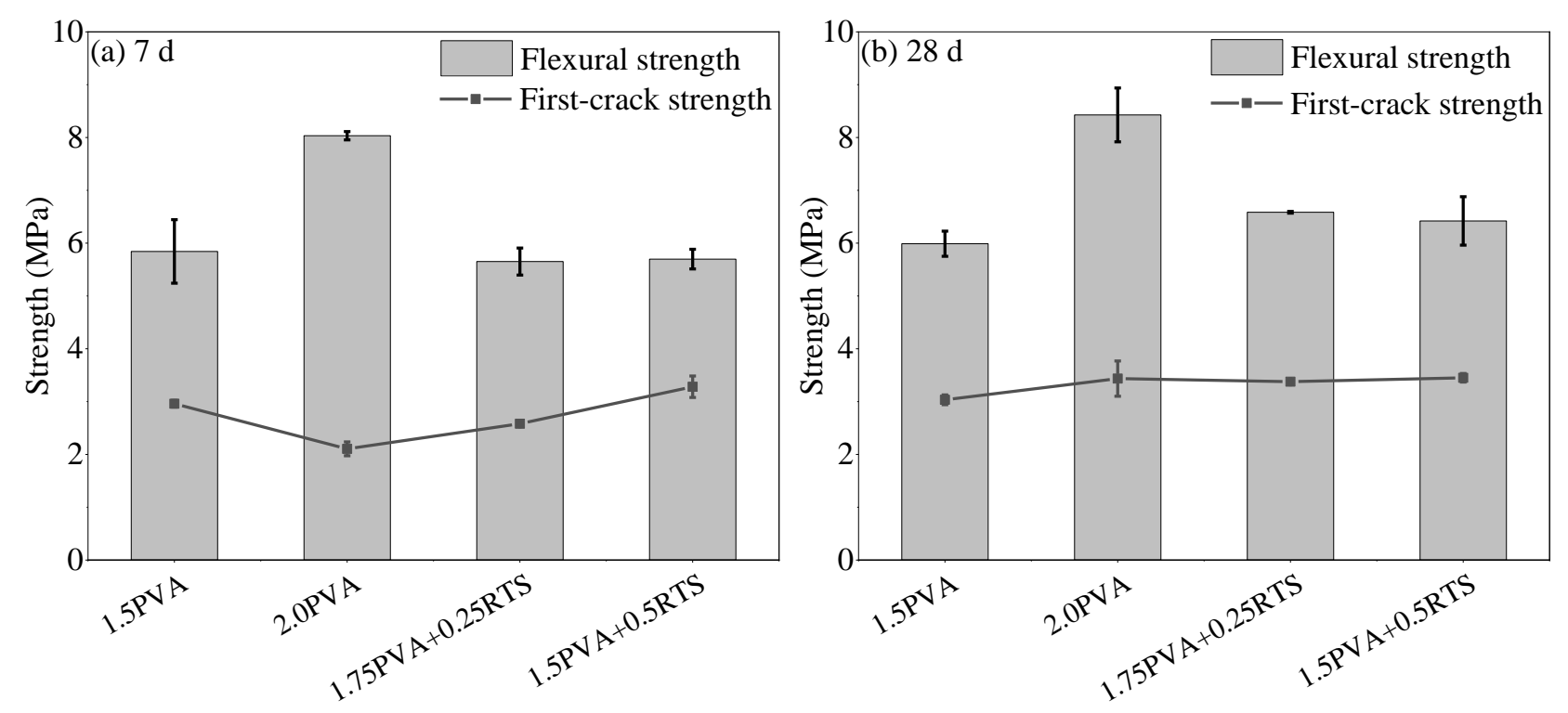

Fig. 13. First-crack strength and flexural strength of SHGC specimens with various hybrid fibre content at $7 \mathrm{~d}$ and $28 \mathrm{~d}$. 


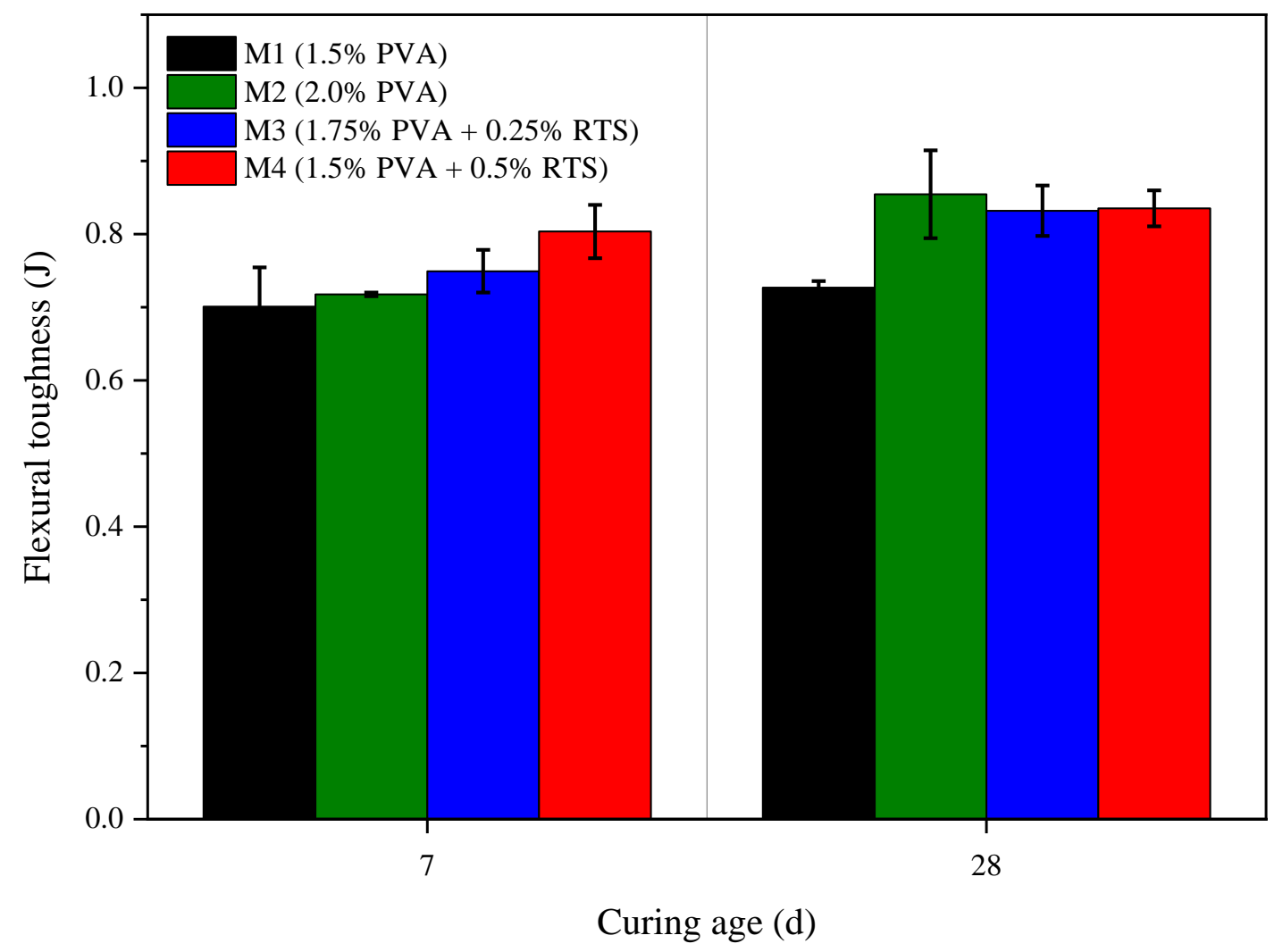

Fig. 14. Flexural toughness of SHGC specimens with various hybrid fibre content at $7 \mathrm{~d}$ and $28 \mathrm{~d}$.
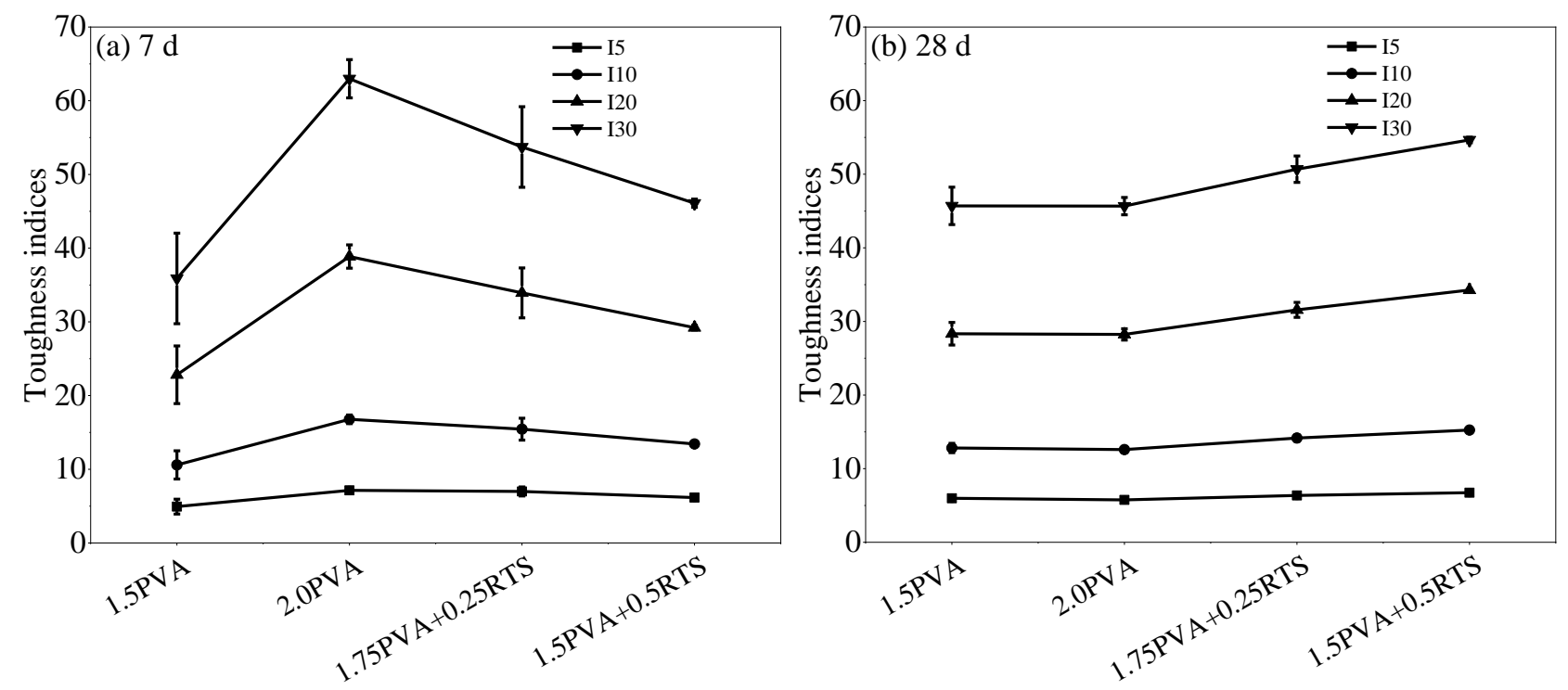

Fig. 15. Toughness indices of SHGC specimens with various hybrid fibre content at $7 \mathrm{~d}$ and $28 \mathrm{~d}$. 


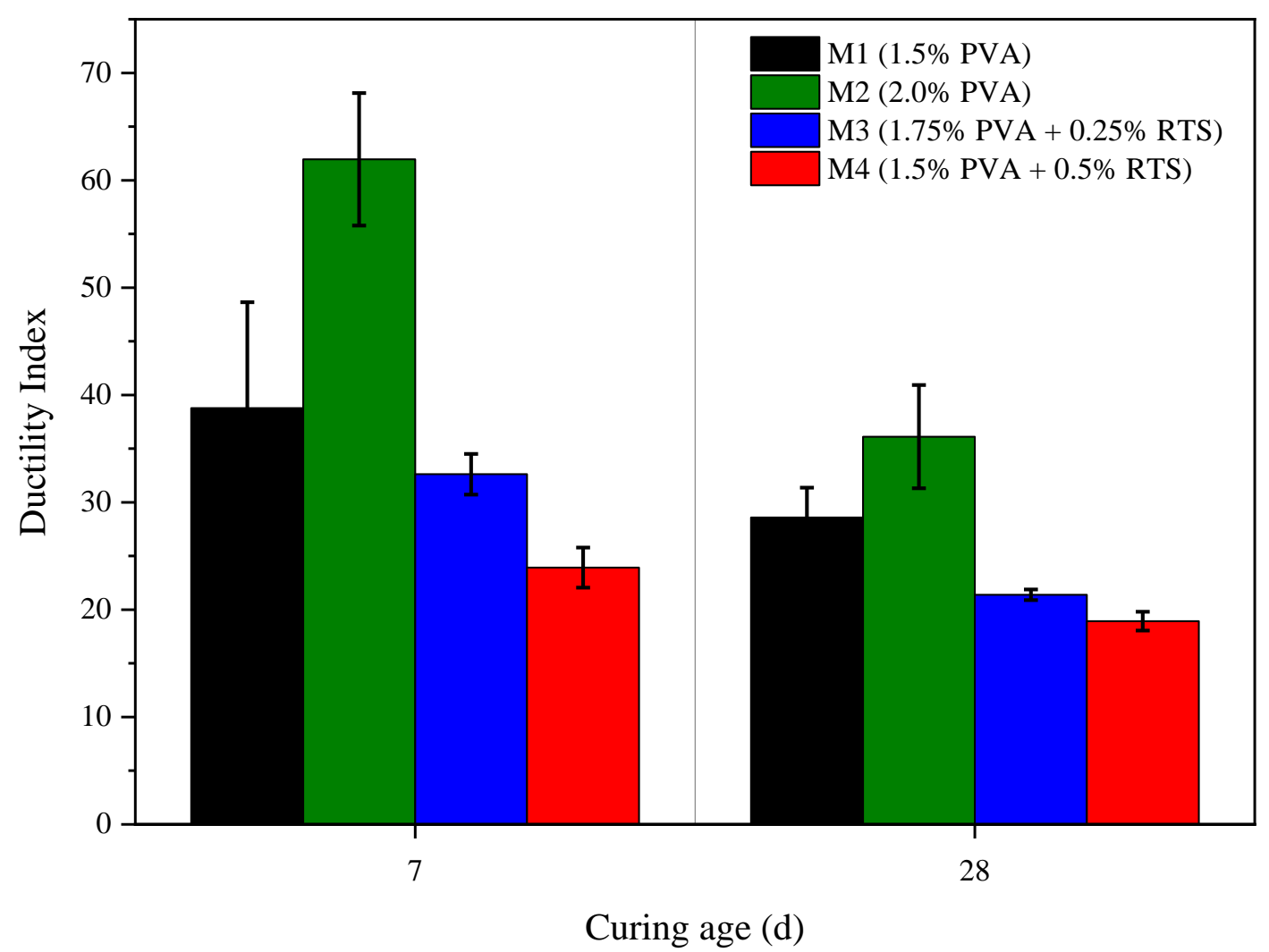

Fig. 16. Ductility index of SHGC specimens with various hybrid fibre content at $7 \mathrm{~d}$ and $28 \mathrm{~d}$. 

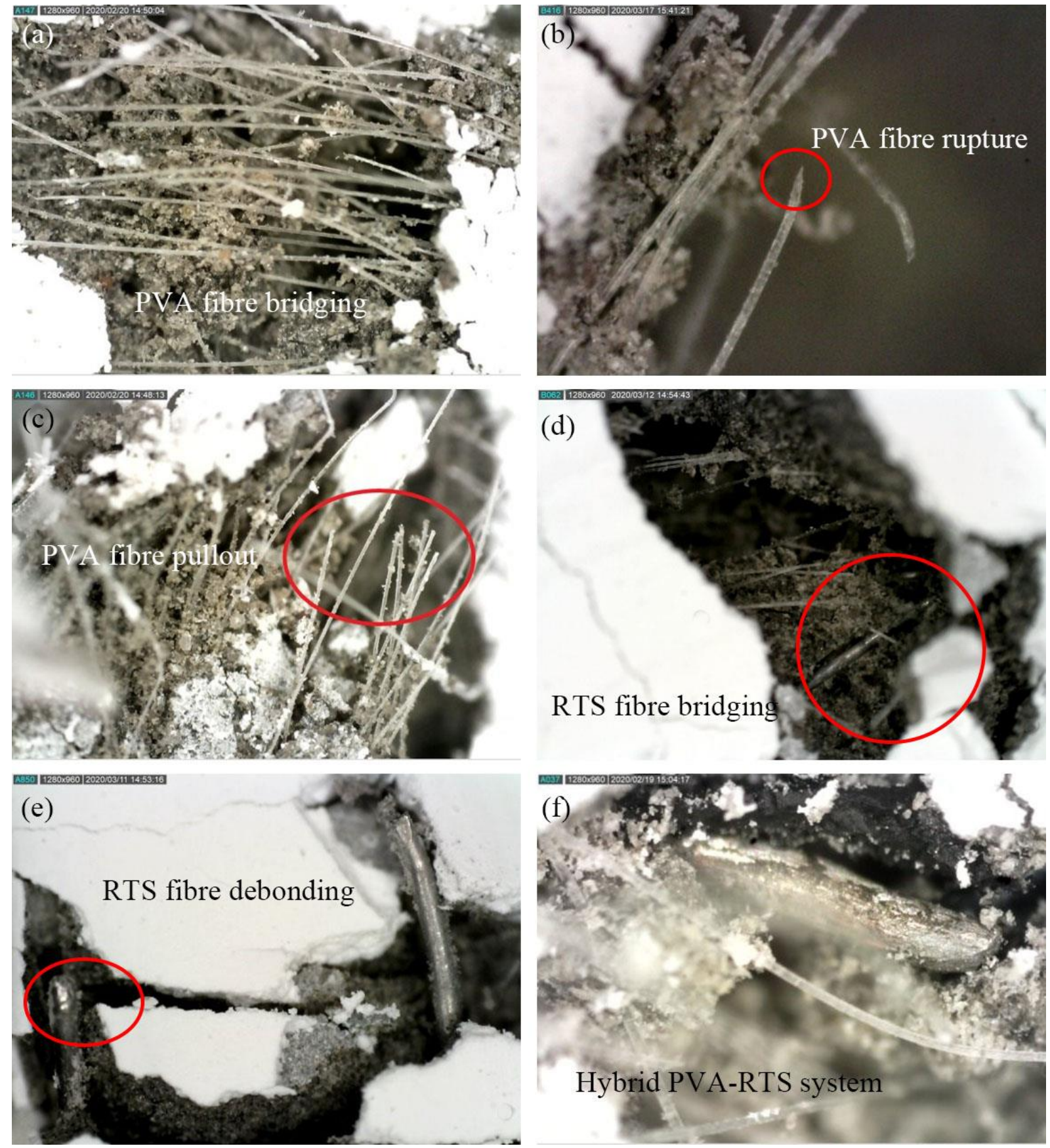

Fig. 17. Toughening mechanisms of SHGC specimens: (a) PVA fibre bridging; (b) PVA fibre rupture; (c) PVA fibre pull-out; (d) RTS fibre bridging; (e) RTS fibre debonding; (f) Hybrid PVARTS fibres. 